\title{
Characterization of 6-Mercaptopurine Transport by the SLC43A3-Encoded Nucleobase Transporter ${ }^{[\mathrm{S}}$
}

\author{
Nicholas M. Ruel, Khanh H. Nguyen, Gonzalo Vilas, and James R. Hammond \\ Department of Pharmacology, University of Alberta, Edmonton, Alberta, Canada
}

Received September 11, 2018; accepted March 14, 2019

\section{ABSTRACT}

6-Mercaptopurine (6-MP) is a nucleobase analog used in the treatment of acute lymphoblastic leukemia and inflammatory bowel disorders. However, the mechanisms underlying its transport into target cells have remained elusive. The protein encoded by SLC43A3_1 [equilibrative nucleobase transporter 1 (ENBT1)] has recently been shown to transport endogenous nucleobases. A splice variant (SLC43A3_2), encoding a protein with 13 additional amino acids in the first extracellular loop, is also expressed but its function is unknown. We hypothesized that 6-MP is a substrate for both variants of ENBT1. Human embryonic kidney 293 (HEK293) cells (lacking endogenous ENBT1 activity) were transfected with each of the coding region variants of SLC43A3. ENBT1 function was assessed via the rate of flux of $\left[{ }^{3} \mathrm{H}\right]$ adenine and $\left[{ }^{14} \mathrm{C}\right] 6-\mathrm{MP}$ across the plasma membrane. Both SLC43A3 variants encoded proteins with similar functional properties. $\left[{ }^{14} \mathrm{C}\right] 6-\mathrm{MP}$ and $\left[{ }^{3} \mathrm{H}\right]$ adenine had $K_{\mathrm{m}}$ values $( \pm$ S.D.) of $163 \pm$ 126 and $37 \pm 26 \mu \mathrm{M}$, respectively, for this system. Decynium22, 6-thioguanine, and 6-methylmercaptopurine inhibited 6-MP uptake with $K_{i}$ values of $1.0 \pm 0.4,67 \pm 30$, and $73 \pm 20 \mu \mathrm{M}$, respectively. ENBT1 also mediated adenine-sensitive efflux of 6-MP from the SLC43A3-HEK293 cells. MRP4 also contributed to the efflux of 6-MP in this model, but was less efficient than ENBT1 in this regard. Furthermore, transfection of HEK293 cells with SLC43A3 increased the sensitivity of the cells to the cytotoxic effects of 6-MP by more than 7-fold. Thus, both variants of ENBT1 are key players in the transfer of 6-MP into and out of cells, and changes in SLC43A3 expression impact 6-MP cytotoxicity.

\section{Introduction}

Nucleobase analog drugs are used as antiviral and anticancer agents, with one of the most established being 6-mercaptopurine (6-MP) used in the maintenance phase of therapy for acute lymphoblastic leukemia. These compounds are generally prodrugs in that they need to be metabolized by intracellular enzymes to their active phosphorylated derivatives. The first step in this activation process is the transport of the nucleobase analogs into the target cells.

A number of different mechanisms have been proposed for the cellular entry of nucleobase analogs. Early studies suggested that SNBT1, a sodium-dependent nucleobase transporter identified in Lilly Laboratories porcine kidney 1 cells, was the 6-MP transporter (Griffith and Jarvis, 1993). However, this was found to be a defective pseudogene in humans (Yamamoto et al., 2010), and is thus not relevant to the clinical actions of these agents. OAT1 and OAT3 have also been shown to mediate the transport of nucleobase drugs such as 6-MP (Mori et al., 2004), but these transporters are limited in their expression profile and are notably absent in leukemia cells

This work was supported by funding from the Cancer Research Society (Canada) [Grant 21355 (to J.R.H.)]

https://doi.org/10.1124/mol.118.114389.

S This article has supplemental material available at molpharm. aspetjournals.org.
(Burckhardt, 2012). The nucleoside transporters hENT1 and hENT2 can also transport nucleobases including 6-MP, but with low affinity $\left(K_{\mathrm{m}}\right.$ values greater than $1 \mathrm{mM} ; 1000$-fold higher than therapeutic levels of 6-MP) (Yao et al., 2011). An earlier study using mouse ENT2-overexpressing Cos-7 cells reported that 6-MP had a value of $14 \mu \mathrm{M} K_{\mathrm{m}}$ for ENT2 (Nagai et al., 2007), suggesting that there may be species differences in ENT2 affinity for 6-MP. In 2007, we characterized a novel nucleobase transport system in human cardiac microvascular endothelial cells and gave it the designation equilibrative nucleobase transporter 1 (ENBT1) (Bone and Hammond, 2007). Using transporter-selective inhibitors, we determined that ENBT1 was distinct from any of the aforementioned putative nucleobase transporters, and was blocked by nucleobase analogs such as 6-MP and 6-thioguanine (6-TG) at concentrations in the low micromolar range. We also described ENBT1 activity in a variety of other cell lines including human U-2 osteosarcoma, rat UMR-106 osteosarcoma, Madin-Darby canine kidney II (MDCKII), a nucleoside transport deficient subline of porcine kidney 15 , and rat microvascular endothelial cells, but, notably, not in human embryonic kidney 293 (HEK293) cells (Bone and Hammond, 2007). However, the gene encoding ENBT1 was not known at that time, and other than our group subsequently showing that ENBT1 could be modulated by oxidative stress in an ischemia-reperfusion injury model (Bone et al., 2014), no further analysis was done.

ABBREVIATIONS: 6-MP, 6-mercaptopurine; 6-TG, 6-thioguanine; DY, dipyridamole; ENBT1, equilibrative nucleobase transporter 1; G418, geneticin; HEK293, human embryonic kidney 293; HRP, horseradish peroxidase; MDCKII, Madin-Darby canine kidney II; MMP, 6methylmercaptopurine; MTX, methotrexate; PCR, polymerase chain reaction; siRNA, small interfering RNA; TBS, Tris-buffered saline; TBS-TM, Tris-buffered saline with Tween-20 and skim milk powder; TPMT, thiopurine methyltransferase. 
In late 2015, SLC43A3, an orphan member of the amino acid transporter gene family (Bodoy et al., 2013), was shown to encode a protein that led to the cellular uptake of the nucleobases adenine and hypoxanthine when expressed in MDCKII cells (Furukawa et al., 2015), with characteristics almost identical to those that we described previously for ENBT1 (Bone and Hammond, 2007). Those investigators also showed that the SLC43A3-encoded transporter could be inhibited by 6-MP. SLC43A3 is expressed at low-to-moderate levels in most tissues, including bone marrow, and has been identified in myeloid and lymphoid cell lines (Human Protein Atlas; https://www.proteinatlas.org/) (Thul et al., 2017). However, none of the aforementioned studies considered the fact that SLC43A3 exists as multiple splice variants. Many of the variants differ in the $5^{\prime}$-untranslated region, but two encode full-length proteins that differ in the absence (SLC43A3_1) or presence (SLC43A3_2) of a 13 amino acid insert in the first predicted extracellular loop (Fig. 1). The study examining recombinant SLC43A3 expression in MDCKII cells used the isoform 1 variant (Furukawa et al., 2015). There have been no studies done on the functional characteristics of the protein encoded by SLC43A3_2, nor has 6-MP actually been shown to be a substrate for either of these transporter variants. If the two SLC43A3 isoforms differ in function or substrate selectivity, their differential expression in cells may impact the effectiveness of nucleobase analog drug substrates. We report herein on the characteristics of adenine and 6-MP transport by the ENBT1 variants encoded by SLC43A3_1 and SLC43A3_2 expressed in HEK293 cells.

\section{Materials and Methods}

Materials. $\left[2,8-{ }^{3} \mathrm{H}\right]$ adenine $(20-40 \mathrm{Ci} / \mathrm{mmol}),\left[8-{ }^{14} \mathrm{C}\right]-6-\mathrm{MP}(50-60$ $\mathrm{mCi} / \mathrm{mmol})$, and $\left[{ }^{3} \mathrm{H}\right]$ water $(1 \mathrm{mCi} / \mathrm{g})$ were obtained from Moravek Biochemicals (Brea, CA). 6-TG, hypoxanthine, 6-methylmercaptopurine (MMP), 2-chloroadenosine, adenine, adenosine, 3-(4,5-dimethylthiazol2-yl)-2,5-diphenyltetrazolium bromide, nitrobenzylthioinosine, dipyridamole (DY), geneticin (G418), Dulbecco's modified Eagle's medium, and amphotericin B were purchased from Sigma-Aldrich (St. Louis, MO). Calf serum was obtained from GE Healthcare Hyclone (Logan, UT). All primers were ordered through Integrated DNA Technologies (Coralville, IA). Agarose, oligo (dT) ${ }_{12-18}$ primer, and M-MLV Reverse Transcriptase came from Invitrogen (Burlington, ON). The $100 \mathrm{bp}$ DNA Ladder was supplied by Truin Science (Edmonton, AB, Canada). Power Up SYBR Green and TRIzol Reagent were supplied by Life Technologies (Burlington, ON, Canada). Antibodies used included mouse monoclonal anti-Myc (clone 4A6, 05-724, lot 2585792; EMD Millipore), rabbit polyclonal anti-SLC43A3 (HPA030551, lot R31257; Sigma-Aldrich), and mouse monoclonal anti- $\beta$-actin (C4, sc-47778, lot D1713; Santa Cruz Biotechnology Inc., Dallas, TX). Horseradish peroxidase (HRP)conjugated secondary antibodies (donkey anti-rabbit IgG-HRP, sc-2313, lot LK0312) and mouse IgGk binding protein conjugated to HRP

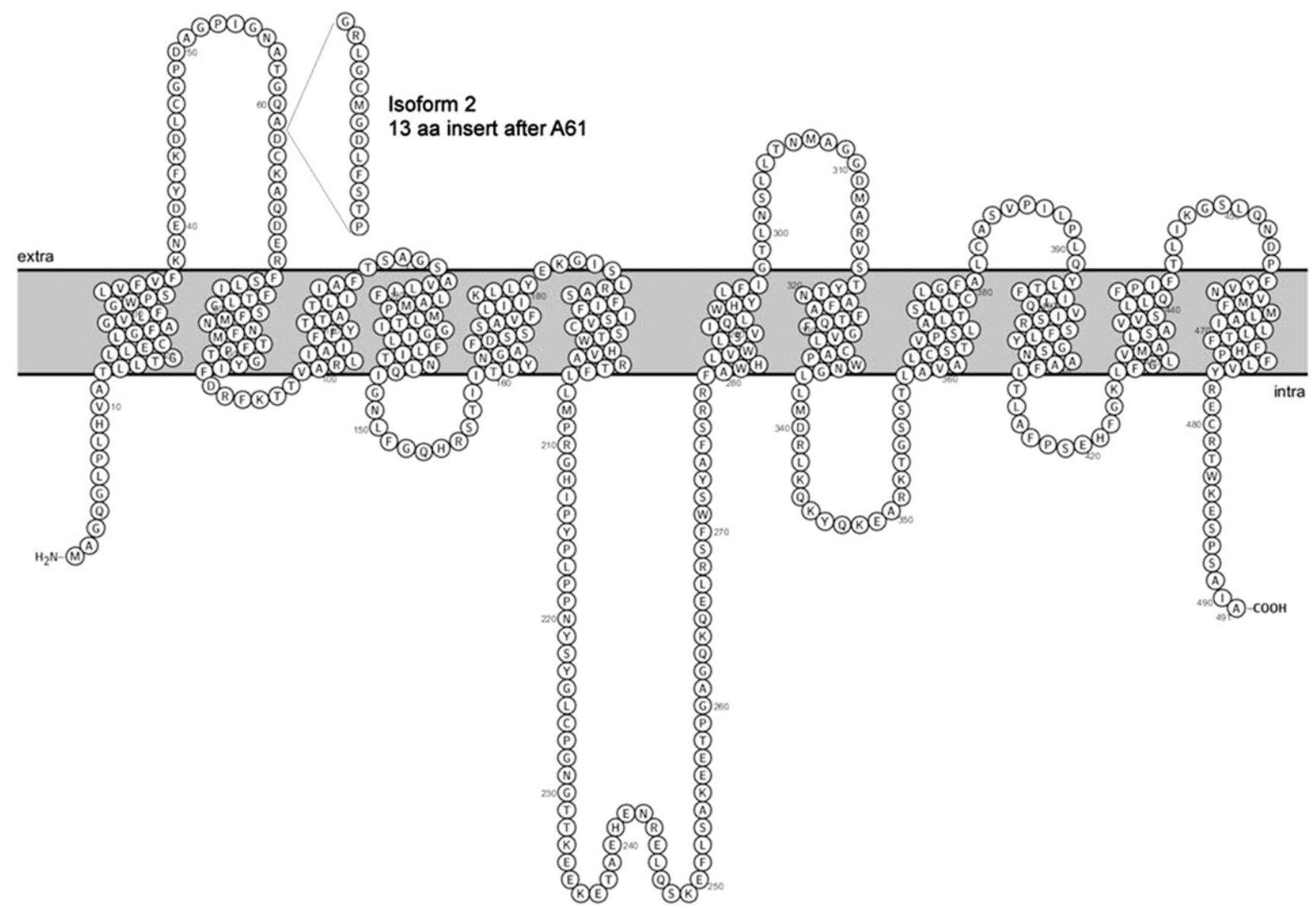

Fig. 1. Predicted topology of ENBT1. Sequence shown is for the protein encoded by SLC43A3_1 (ENBT1.1). The 13 amino acid insert in ENBT1.2 (encoded by SLC43A3_2) after the alanine at position 61 is indicated. Structure was generated with Protter (http://wlab.ethz.ch/protter/start/) (Omasits et al., 2014). 
(BP-HRP, sc-516102, lot F1016) were also purchased from Santa Cruz Biotechnology. Decynium-22, ceefourin-1, and zaprinast were obtained from Tocris Bioscience (Oakville, ON, Canada), and methotrexate (MTX) was obtained from Alfa Aesar (Tewksbury, MA). HEK293 cells were purchased from ATCC (Manassas, VA).

Myc-SLC43A3 Plasmid Construct. Oligonucleotides corresponding to the coding region of isoform 1 (NM_001278201) or isoform 2 (NM_001278206) of SLC43A3, with an N-terminal myc-epitope tag, were prepared in the GeneArt Cloning pMA plasmid by Invitrogen. The Myc-SLC43A3 sequences were transferred to the mammalian cloning vector pcDNA3.1 (-) using the Xbal (5') and KpnI (3') restriction enzymes. The inserts were sequenced in both directions to confirm integrity and then used to transfect HEK293 cells using the calcium phosphate method (Kingston et al., 2003). Cells expressing SLC43A3 were selected based on their resistance to $600 \mu \mathrm{g} / \mathrm{ml} \mathrm{G418}$ using standard procedures. Cells stably transfected with the empty pcDNA3.1 vector were also tested to assess the impact of the transfection procedure and G418 on the measured parameters.

Cell Culture. HEK293 cells were cultured in Dulbecco's modified Eagle's medium with 5\% calf serum, $5 \%$ fetal bovine serum, penicillin $(100 \mathrm{U} / \mathrm{ml})$, streptomycin $(100 \mu \mathrm{g} / \mathrm{ml})$, sodium pyruvate $(1 \mathrm{mM})$, and amphotericin B $(0.5 \mu \mathrm{g} / \mathrm{ml})$. G418 was added $(120 \mu \mathrm{g} / \mathrm{ml})$ in the SLC43A3-HEK293 cell media to maintain selection pressure on the stable transfectants. The HEK293 cells were removed from flasks by exposure to $0.05 \%$ trypsin/EDTA for 5 minutes at $37^{\circ} \mathrm{C}$ and the suspended cells were washed in the appropriate buffer solution (without G418) immediately prior to use in subsequent assays.

Polymerase Chain Reaction. Cells from confluent $10-\mathrm{cm}$ plates were suspended in $1 \mathrm{ml}$ of TRIzol reagent and homogenized for extraction of RNA according to the manufacturer's protocol (Invitrogen). Total RNA concentration and purity were determined using a Nanodrop 2000 spectrophotometer (Life Technologies Inc.). For qualitative polymerase chain reaction (PCR), $5 \mu \mathrm{g}$ of total RNA was reverse transcribed to cDNA using Oligo $(\mathrm{dT})_{12-18}$ primer and M-MLV Reverse Transcriptase, and amplified using recombinant Taq DNA Polymerase (Thermo Scientific Canada) and primers designed for SLC43A3 (forward primer: 5'-GGAACTCCGCTCCTTCT; reverse primer 3'-TGATCACTTGCAGGATGAAG), or glyceraldehyde-3-phosphate dehydrogenase (forward primer: 5'-ACATCATCCCTGCCTCTAC; reverse primer 3 '-CCTGTTGCTGTAGCCAAAT). Primer efficiency and melt curves were assessed prior to their use for gene expression analysis. The following conditions were used for amplification: 3 minutes at $95^{\circ} \mathrm{C}$, followed by 40 cycles of 30 seconds at $95^{\circ} \mathrm{C}$; 30 seconds at $56^{\circ} \mathrm{C}$; and 60 seconds at $72^{\circ} \mathrm{C}$, followed by extension for 10 minutes at $72^{\circ} \mathrm{C}$ in a BioRad T-100 Thermocycler. Semiquantitative PCR was conducted using cDNA ( $100 \mathrm{ng} /$ well) prepared as described previously with the primer sets shown in (Supplemental Table 1) using Power Up SYBR Green fluorescence on a Roche Light Cycler 480 System (Cardiovascular Research Centre, Edmonton, Canada). Semiquantitative PCR conditions were: 2 minutes at $50^{\circ} \mathrm{C}$ (UDG activation); 2 minutes at $95^{\circ} \mathrm{C}$ (denaturation), followed by 45 cycles of 15 seconds at $95^{\circ} \mathrm{C}$; and 60 seconds at $60^{\circ} \mathrm{C}$ for amplification, with a final melt curve analysis. Gene expression was normalized to glyceraldehyde-3-phosphate dehydrogenase and analyzed relative to expression in the untransfected HEK293 cells using the $\Delta \Delta \mathrm{Ct}$ method. Glyceraldehyde-3-phosphate dehydrogenase $\mathrm{Ct}$ values were relatively consistent across the cell models used (18.8 \pm $0.2,19.4 \pm 0.3,16.9 \pm 0.3$, and $19.0 \pm 0.3$ for the untransfected HEK293 cells and the cells transfected with pcDNA3.1, SLC43A3_1, and SLC43A3_2, respectively, $n=5$ ).

Immunoblotting. Samples were prepared in radioimmunoprecipitation assay buffer ( $150 \mathrm{mM} \mathrm{NaCl}, 50 \mathrm{mM}$ Tris, $1 \% \mathrm{NP}-40,0.5 \%$ sodium deoxycholate, $1 \%$ SDS) containing protease inhibitors. Samples were adjusted to $2 \%(\mathrm{v} / \mathrm{v}) \beta$-mercaptoethanol, and resolved by SDS-PAGE on $12.5 \%(\mathrm{w} / \mathrm{v})$ acrylamide gels. Proteins were electrotransferred onto Immobilon-P polyvinylidene fluoride membranes (Millipore Corporation) for 1.5 hours at a constant current of $280 \mathrm{~mA}$. After transfer, membranes were rinsed in Tris-buffered saline [(TBS); $0.15 \mathrm{M} \mathrm{NaCl}, 50 \mathrm{mM}$ Tris, $\mathrm{pH} 7.5]$ and incubated with TBS-TM (TBS containing $0.2 \% \mathrm{v} / \mathrm{v}$ Tween-20 and $5 \% \mathrm{w} / \mathrm{v}$ skim milk powder) for 1 hour at room temperature with gentle rocking to block nonspecific binding. Membranes were then incubated for 16 hours at $4^{\circ} \mathrm{C}$ with gentle rocking in the presence of either mouse anti-Myc, rabbit anti-SLC43A3, or mouse anti- $\beta$-actin at 1:1000, 1:250, and 1 : 500 dilutions, respectively, in TBS-TM (containing $1 \%$ skim milk powder). After successive washes with TBS-TM the membranes were incubated with a 1:5000 or 1:3000 dilution of donkey anti-rabbit IgGHRP or m-IgGk binding protein HRP, respectively, in TBS-TM for 1 hour at room temperature and further washed with TBS containing $0.2 \%(\mathrm{v} / \mathrm{v})$ Tween-20. Proteins were detected using an enhanced chemiluminescence western blot substrate (EMD Millipore) and visualized using a ChemiDoc XRS + System (Bio-Rad Laboratories).

Nucleobase Uptake. Cells were suspended in nominally sodiumfree buffer (to eliminate potential contribution of sodium-dependent transporters) ( $N$-methylglucamine buffer; $140 \mathrm{mM} N$-methylglucamine, $5 \mathrm{mM} \mathrm{KCl}, 4.2 \mathrm{mM} \mathrm{KHCO} 3,0.36 \mathrm{mM} \mathrm{K}_{2} \mathrm{HPO}_{4}, 0.44 \mathrm{mM}$ $\mathrm{KH}_{2} \mathrm{PO}_{4}, 10 \mathrm{mM}$ HEPES, $0.5 \mathrm{mM} \mathrm{MgCl}, 1.3 \mathrm{mM} \mathrm{CaCl}_{2}, \mathrm{pH} 7.4$ ) containing $500 \mathrm{nM}$ DY (to block potential ENT1/ENT2-mediated uptake) and incubated for 15 minutes at room temperature prior to assay. Cellular uptake was initiated by adding $250 \mu \mathrm{l}$ cell suspension to $250 \mu \mathrm{l}\left[{ }^{14} \mathrm{C}\right] 6-\mathrm{MP}$ or $\left[{ }^{3} \mathrm{H}\right]$ adenine layered over $21: 4$ silicone:mineral oil (v:v) $(200 \mu \mathrm{l})$ in $1.5 \mathrm{ml}$ microcentrifuge tubes. The uptake reaction was terminated after specified times by centrifugation of the cells through the oil layer at $\sim 10,000 \mathrm{~g}$. The aqueous layer was aspirated and the upper tube was washed with $\sim 1 \mathrm{ml}$ of $N$-methylglucamine buffer prior to removal of the oil layer. The resulting cell pellet was digested in $1 \mathrm{M} \mathrm{NaOH}$ overnight ( 16 hours), with aliquots of digested cells assessed for radioactive content using standard liquid scintillation counting techniques in a Beckman Coulter LS6500 scintillation system. Nonmediated uptake was defined as uptake of $\left[{ }^{3} \mathrm{H}\right]$ adenine by untransfected HEK293 cells, or uptake of $\left[{ }^{14} \mathrm{C}\right] 6-\mathrm{MP}$ by cells in the presence of $1 \mathrm{mM}$ adenine. Mediated uptake was defined as the difference between the total and nonmediated uptake components. Cell volume (in microliters) was estimated by incubating cells with $\left[{ }^{3} \mathrm{H}\right]$ water for 3 minutes, centrifuging the cells through the oil layer, sampling $100 \mu \mathrm{l}$ of the supernatant, and then processing as previously described. Total cellular water volume was determined from the ratio of the dpm of the cell pellet to the dpm of the supernatant, allowing for interexperimental normalization via calculation of picomoles of substrate accumulated per microliter of cell-associated water.

6-MP Efflux. Cells were removed from confluent T175 flasks and suspended in sodium-free buffer as described for the nucleobase uptake assays. Cell number was determined using Trypan Blue Stain (Hyclone; GE Healthcare) on a BioRad TC10 Automated Cell Counter prior to loading the cells with radioactive substrate. Cells were loaded with $100 \mu \mathrm{M}\left[{ }^{14} \mathrm{C}\right] 6-\mathrm{MP}$ for 30 seconds and then centrifuged at $1000 \mathrm{~g}$ for 30 seconds to lightly pellet the cells. Supernatant was removed and the cell pellets were rapidly suspended in sodium-free buffer ( \pm inhibitors) to initiate efflux. Aliquots $(500 \mu \mathrm{l})$ of this cell suspension were layered over 21:4 silicone:mineral oil (v:v) in a $1.5 \mathrm{ml}$ microcentrifuge tube and centrifuged at specified time points. The cell pellets were then washed and incubated in $1 \mathrm{M} \mathrm{NaOH}$ overnight and processed as previously described for the nucleobase uptake assays to determine the intracellular $\left[{ }^{14} \mathrm{C}\right]$ content. In experiments where $1 \mathrm{mM}$ adenine was used, the initial load of $\left[{ }^{14} \mathrm{C}\right] 6-\mathrm{MP}$ (time zero) was determined by extrapolation of the exponential decay curve fit to the data obtained in the presence of $1 \mathrm{mM}$ adenine. In experiments where $1 \mathrm{mM}$ adenine was not used, the initial load of $\left[{ }^{14} \mathrm{C}\right] 6-\mathrm{MP}$ (time zero) was determined by centrifuging an aliquot $(500 \mu \mathrm{l})$ of the cells immediately following the loading step and processing as described previously. No difference was noted between these two methods in determination of initial load for these experiments.

Cell Viability. Cells were seeded into a 24 -well plate at a density of $5 \times 10^{4}$ cells/well in culture medium and allowed to attach overnight. Culture medium was removed the following day and replaced by medium containing $6-\mathrm{MP}(75 \mathrm{nM}-1.28 \mathrm{mM})$ and incubated 
for 48 hours at $37^{\circ} \mathrm{C}$ in a humidified $5 \% \mathrm{CO}_{2}$ atmosphere. In some cases, the ENT1/ENT2 inhibitor DY or the MRP4 and MRP5 inhibitors ceefourin-1 and zaprinast, respectively, were included in the medium to assess the influence of these transporters on 6-MP cytotoxicity. After 48 hours, the medium was removed and replaced with Dulbecco's PBS (137 mM NaCl, $2.7 \mathrm{mM} \mathrm{KCl}, 6.3 \mathrm{mM} \mathrm{Na} 2 \mathrm{HPO}_{4}$, $\left.1.5 \mathrm{mM} \mathrm{KH}_{2} \mathrm{PO}_{4}, 0.5 \mathrm{mM} \mathrm{MgCl}_{2} \cdot 6 \mathrm{H}_{2} 0,0.9 \mathrm{mM} \mathrm{CaCl}_{2} \cdot 2 \mathrm{H}_{2} 0, \mathrm{pH} 7.4\right)$ containing 3-(4,5-dimethylthiazol-2-yl)-2,5-diphenyltetrazolium bromide $(1 \mathrm{mg} / \mathrm{ml})$ for 90 minutes. Formazan crystals that formed were solubilized in $450 \mu \mathrm{l}$ of DMSO and absorbance was measured at $570 \mathrm{~nm}$ in a Spectra Max 340 plate reader (Molecular Devices, Sunnyvale, CA).

Data Analysis and Statistics. Data are expressed as mean \pm S.D. Sample size was predetermined as $N=5$ (five independent experiments with two to three internal replicates), which is the minimum needed to define statistical differences based on the known historical variability inherent in these types of studies. In some circumstances, where higher variability was seen due to methodological issues (e.g., the rapid uptake profiles using the HEK293SLC43A3_1 cells), an additional one or two experiments were added. Nonlinear curves were fitted to data, and statistical analyses were done using GraphPad Prism 8.01 software. In all cases, if the $P$ value determined from a statistical test was less than 0.5 , the difference was considered significant and the null hypothesis (no difference between data sets) was rejected. Efflux data were assessed using both one- and two-phase decay profiles and the curves that fit best to the data were determined by the $F$ test. Influx data were best represented by a onephase association profile (vs. two-phase). Significant differences between groups were assessed using Student's $t$ test, corrected for multiple comparisons with the Holm-Sidak method. For inhibition analyses, the $K_{\mathrm{i}}$ values were determined from the $\mathrm{IC}_{50}$ values using the specified substrate concentration [S], based on the Cheng-Prusoff equation $K_{\mathrm{i}}=\mathrm{IC}_{50} /\left(1+[\mathrm{S}] / K_{\mathrm{m}}\right)($ Cheng and Prusoff, 1973) and the respective $K_{\mathrm{m}}$ values for 6 -MP transport determined in this study.

\section{Results}

Transfection of HEK293 Cells with SLC43A3. To ensure that our stable cell transfection protocol was successful, qualitative PCR was conducted using cDNA prepared from untransfected HEK293 and SLC43A3-transfected HEK293 cells (Fig. 2A). The untransfected and vector-only transfected HEK293 cells expressed minimal levels of SLC43A3 isoform 1 , and there was no detectable isoform 2 transcript, supporting prior data showing that these cells do not have measurable ENBT1-mediated nucleobase flux capacity (Bone and Hammond, 2007). In contrast, the SLC43A3-transfected cell lines expressed high levels of the respective SLC43A3 transcript (Fig. 2A). Both SLC43A3 isoform-encoded proteins were also detected by immunoblotting using either anti-SLC43A3 (Fig. 2B) or anti-Myc (Fig. 2C) antibodies, with about 6-fold more isoform 1 detected than isoform 2 (relative to $\beta$-actin). Henceforth, we will refer to the encoded proteins as ENBT1.1 (isoform 1) and ENBT1.2 (isoform 2).

Gene Expression Analysis. The more sensitive semiquantitative PCR analyses indicated that HEK293 cells did express low levels of SLC43A3, but the SLC43A3_1- and SLC43A3_2-transfected cells had 3240- and 840-fold higher levels of the respective transcript than untransfected HEK293 cells (Fig. 3A). Interestingly, cells stably transfected with the empty vector, pcDNA3.1, showed a 10 -fold decrease in endogenous SLC43A3 expression (Fig. 3A). To determine if transfection of HEK293 cells with SLC43A3, or the vector alone, led to compensatory changes in other relevant genes, we examined the level of expression of the nucleoside transporters SLC29A1 (ENT1), SLC29A2 (ENT2), and SLC29A4 (ENT4), the efflux pumps ABCC4 (MRP4) and ABCC5 (MRP5), and the intracellular enzymes involved in 6-MP metabolism, thiopurine methyltransferase (TPMT) and hypoxanthine-guanine phosphoribosyltransferase. ABCC5 was downregulated and TPMT and hypoxanthine-guanine phosphoribosyltransferase were upregulated in the vector-transfected cells (Fig. 3B). In contrast, in cells transfected with SLC43A3, the transcripts for SLC29A2, ABCC4, and ABCC5 were found to be downregulated in both the SLC43A3_1-transfected (Fig. 3C) and SLC43A3_2-transfected (Fig. 3D) cells relative to control HEK293 cells. In addition, the SLC43A3_2-transfected cells showed a significant decrease in SLC29A4 transcript (Fig. 3D). No changes were noted for the other transcripts measured.

$\left[{ }^{3} \mathbf{H}\right]$ Adenine Influx. Untransfected HEK293 cells, or cells transfected with empty vector, exhibited minimal timedependent uptake of $\left[{ }^{3} \mathrm{H}\right]$ adenine (Fig. 4, A and B). In contrast, $\left[{ }^{3} \mathrm{H}\right]$ adenine influx by cells transfected with SLC43A3_1 was time dependent with steady-state accumulation of $100 \mu \mathrm{M}$ $\left[{ }^{3} \mathrm{H}\right]$ adenine $(67 \pm 11 \mathrm{pmol} / \mu \mathrm{l})$ achieved within 10 seconds (Fig. 4A), reflecting the high level of expression of ENBT1.1 in these cells (see Fig. 2). When the background (untransfected HEK293 cell-associated $\left[{ }^{3} \mathrm{H}\right]$ adenine) was subtracted, an initial rate of ENBT1.1-mediated transport of $18 \pm 9 \mathrm{pmol} / \mu \mathrm{l}$

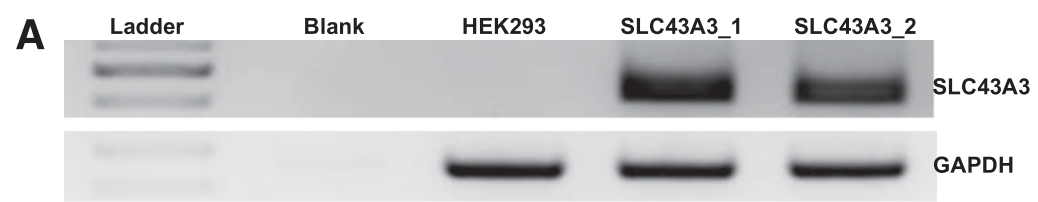

B

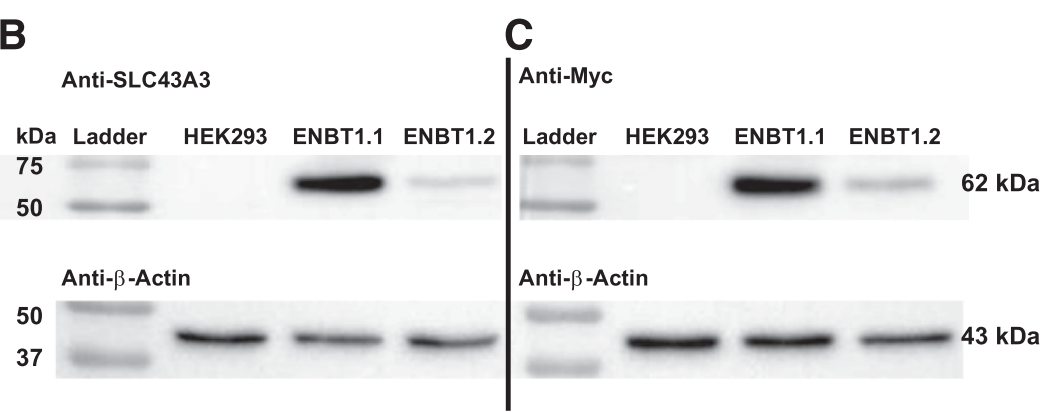

Fig. 2. Stable transfection of HEK293 cells with SLC43A3_1 and SLC43A3_2. (A) Transfection of HEK293 cells with SLC43A3 was confirmed using PCR with the primers specific for SLC43A3 (top) and glyceraldehyde-3-phosphate dehydrogenase (GAPDH) (bottom) shown in (Supplemental Table 1). cDNA was prepared from total RNA isolated from untransfected cells (HEK293) or HEK293 cells stably transfected with SLC43A3_1 or SLC43A3_2. (B) Membranes were prepared from HEK293 cells and cells transfected with SLC43A3_1 (ENBT1.1) and SLC43A3_2 (ENBT1.2). Samples were resolved on SDS-PAGE gels, transferred to polyvinyl membranes and probed with anti-SLC43A3 and anti- $\beta$-actin antibodies. (C) Parallel immunoblot analyses were performed as described previously, but using anti-myc and anti- $\beta$-actin antibodies. 

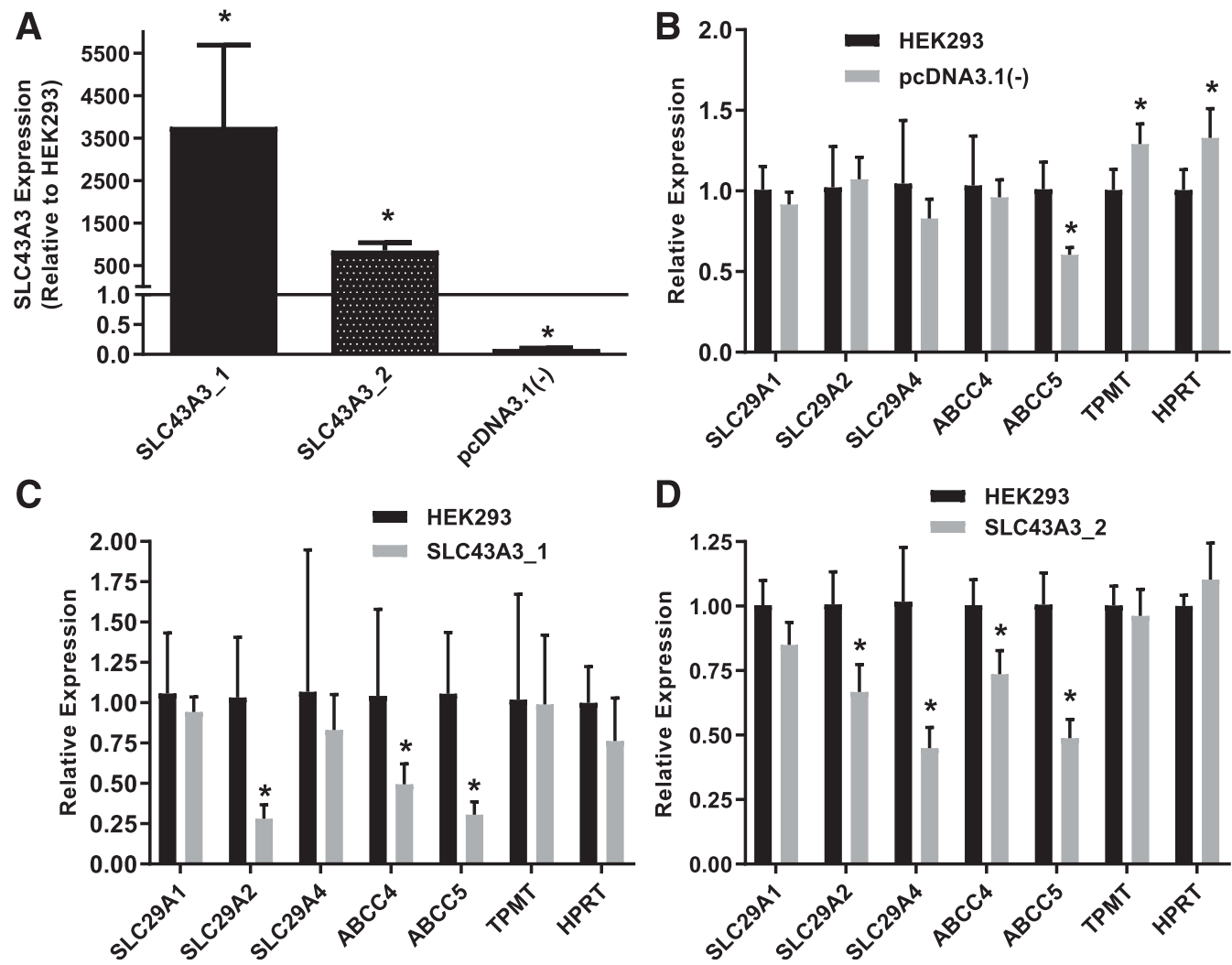

Fig. 3. Compensatory changes in gene expression upon transfection of HEK293 cells with SLC43A3. Gene expression, assessed by semiquantitative PCR, is shown relative to the amount detected in untransfected HEK293 cells. Expression was normalized to glyceraldehyde-3-phosphate dehydrogenase transcript levels in each individual experiment. (A) Relative expression of SLC43A3 in HEK293 cells stably transfected with the respective SLC43A3_1, SLC43A3_2, or empty vector (pcDNA3.1) construct $(N=5$ ). (B-D) Relative expression of ENT1 (SLC29A1), ENT2 (SLC29A2), ENT4 (SLC29A4), MRP4 (ABCC4), and MRP5 (ABCC5), and the enzymes TPMT and hypoxanthine-guanine phosphoribosyltransferase (HPRT) in HEK293 cells transfected with either empty pcDNA3.1 (B), SLC43A3_1 (C), or SLC43A3_2 (D). Bars represent the mean \pm S.D. of five independent samples; * denotes significant difference in expression between untransfected HEK293 cells and transfected HEK293 cells (Student's $t$ test, $P<0.05$, corrected for multiple comparisons with the Holm-Sidak method).

per second (for $100 \mu \mathrm{M}\left[{ }^{3} \mathrm{H}\right]$ adenine) was estimated by extrapolation of the uptake profile to 0.5 seconds. The transport efficiency of this system made it necessary to conduct full-time courses at each substrate concentration to allow determination of transporter kinetics based on initial rates (estimated from uptake at 0.5 seconds derived from curves fitted to each independent experiment). In contrast, ENBT1.2-mediated $\left[{ }^{3} \mathrm{H}\right]$ adenine influx in the SLC43A3_2transfected cells was slower with an initial rate for $100 \mu \mathrm{M}$ $\left[{ }^{3} \mathrm{H}\right]$ adenine influx of $6 \pm 2 \mathrm{pmol} / \mu \mathrm{l}$ per second (Fig. $4 \mathrm{~B}$ ), reflecting the relatively lower level of ENBT1.2 protein in the transfected HEK293 cells (Fig. 2B). Thus, initial rates for ENBT1.2-mediated influx were estimated from the experimentally determined 2-second uptake time point. The results of these kinetic experiments are shown in Fig. 4C. $\left[{ }^{3} \mathrm{H}\right]$ adenine transport by ENBT1.1 had a $K_{\mathrm{m}}$ value of $37 \pm 26 \mu \mathrm{M}$ and a $V_{\max }$ value of $34 \pm 6 \mathrm{pmol} / \mu \mathrm{l}$ per second; ENBT1.2 had a $K_{\mathrm{m}}$ value for adenine $(40 \pm 26 \mu \mathrm{M})$ similar to that of ENBT1.1 and a $V_{\max }$ value of $7.9 \pm 1.6 \mathrm{pmol} / \mu \mathrm{l}$ per second.

ENBT1-Mediated $\left[{ }^{14} \mathbf{C}\right] 6-M P$ Influx. Similar studies were then conducted using $\left[{ }^{14} \mathrm{C}\right] 6-\mathrm{MP}$ as the substrate. As seen for the $\left[{ }^{3} \mathrm{H}\right]$ adenine uptake assays, the background uptake of $\left[{ }^{14} \mathrm{C}\right] 6-\mathrm{MP}$ in the untransfected HEK293 cells was higher than expected for this assay protocol. However, this background was not affected by addition of the ENT1/ENT2 inhibitor DY (1 $\mu \mathrm{M})$ (Ward et al., 2000), the pan-nucleoside transporter substrate uridine ( $1 \mathrm{mM}$ ) (Young et al., 2013), or the nucleobase adenine $(1 \mathrm{mM})$, indicating it was not due to the operation of other nucleoside/nucleobase transporters such as ENT1, ENT2, and CNT3 that have been suggested by others to mediate 6-MP uptake (Nagai et al., 2007; Yao et al., 2011). The organic anion transporter inhibitor novobiocin $(300 \mu \mathrm{M})$ (Mori et al., 2004; Duan and You, 2009; Burckhardt, 2012) also did not have an effect on the residual accumulation of $100 \mu \mathrm{M} 6-\mathrm{MP}(17.8 \pm 1.8 \mathrm{pmol} / \mu \mathrm{l}$ per 2 second and $17.2 \pm 1.8 \mathrm{pmol} / \mu \mathrm{l}$ per 2 second in the absence and presence of novobiocin, respectively, $N=5$ ), and the background was not reduced by additional washing steps, suggesting that this remaining $\left[{ }^{14} \mathrm{C}\right]$ was likely cell membrane-associated $\left[{ }^{14} \mathrm{C}\right] 6-\mathrm{MP}$ or nonspecific binding of $\left[{ }^{14} \mathrm{C}\right] 6-\mathrm{MP}$ to the polypropylene centrifuge tubes. HEK293 cells expressing ENBT1.1 accumulated $100 \mu \mathrm{M}$ 6-MP in a time-dependent manner, and this uptake could be inhibited completely by $1 \mathrm{mM}$ adenine (Fig. 5A). Figure 5B shows a similar time course profile for $30 \mu \mathrm{M}$ 6-MP uptake by untransfected and pcDNA3.1-transfected HEK293 cells, and ENBT1.2-expressing HEK293 cells in the presence and absence of $1 \mathrm{mM}$ adenine. As for the ENBT1.1-expressing cells (Fig. 5A), the uptake of 6-MP by ENBT1.2 was inhibited completely by $1 \mathrm{mM}$ adenine, with uptake in the presence of adenine not significantly different from 6 -MP uptake by the untransfected HEK293 cells or vector-only transfected cells 

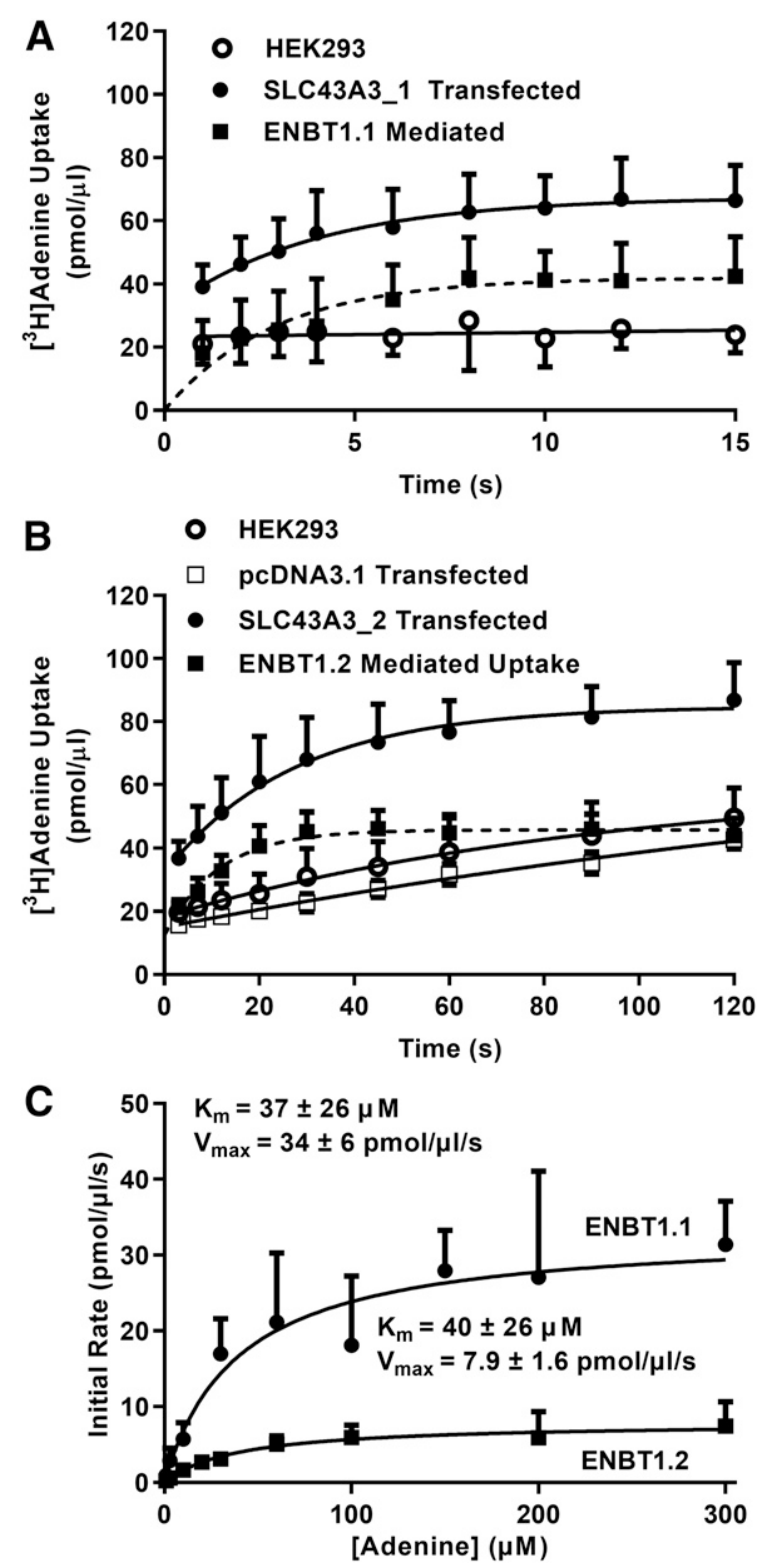

Fig. 4. $\left[{ }^{3} \mathrm{H}\right]$ Adenine transport by SLC43A3-encoded ENBT1. HEK293 cells and cells transfected with SLC43A3 1 (A), SLC43A3 2 (B), or the empty pcDNA3.1 vector (B) were incubated with $100 \mu \mathrm{M}\left[{ }^{3} \mathrm{H}\right]$ adenine at room temperature for the specified times (abscissa) and then centrifuged through oil. Cell pellets were digested overnight in $1 \mathrm{M} \mathrm{NaOH}$ and assessed for $\left[{ }^{3} \mathrm{H}\right]$ content using standard liquid scintillation counting techniques to define picomoles of adenine accumulated per microliter cell pellet (ordinate). ENBT1-mediated uptake was defined as the difference in cellular accumulation by the SLC43A3-transfected cells (SLC43A3HEK293) and that observed in the untransfected HEK293 cells assessed in parallel. Data points represent the mean \pm S.D. of six (A) or five (B) experiments done in duplicate. (C) The kinetics of ENBT1.1- and ENBT1.2mediated uptake of $\left[{ }^{3} \mathrm{H}\right]$ adenine were determined by assessing the uptake of a range of concentrations of $\left[{ }^{3} \mathrm{H}\right]$ adenine (abscissa) as described for (A and B). Initial rates of influx (ordinate) were estimated as the transporter-mediated uptake at 0.5 seconds extrapolated from time course profiles as shown in (A) (ENBT1.1) or directly from the 2-second uptake time point (B) (ENBT1.2). Data shown are the mean \pm S.D. of $N=$ five experiments.

(Fig. 5B). Therefore, 6-MP uptake in the presence of $1 \mathrm{mM}$ adenine was defined as a nontransporter-mediated background in subsequent experiments. The time courses of uptake by ENBT1.1 were constructed for a range of $\left[{ }^{14} \mathrm{C}\right] 6-\mathrm{MP}$ concentrations $(1-300 \mu \mathrm{M})$, with initial rates
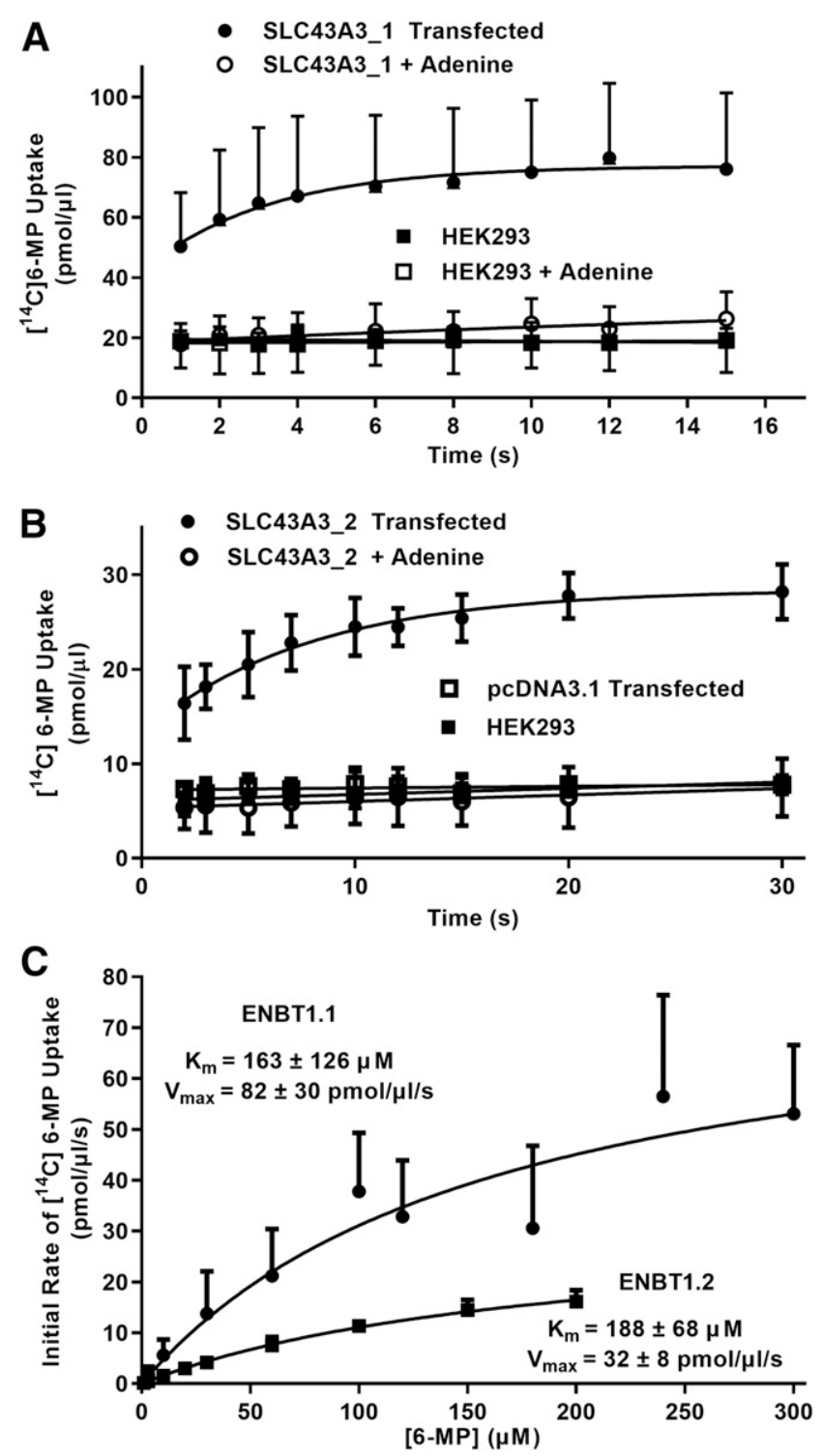

Fig. 5. $\left[{ }^{14} \mathrm{C}\right] 6-\mathrm{MP}$ transport by SLC43A3-encoded ENBT1. HEK293 cells and cells transfected with SLC43A3 1 (A), SLC43A3 2 (B), or empty pcDNA3.1 (B) were incubated with $100 \mu \mathrm{M}$ (A) or $30 \mu \mathrm{M}$ (B) $\left[{ }^{14} \mathrm{C}\right] 6-\mathrm{MP}$ at room temperature, in the presence and absence of $1 \mathrm{mM}$ adenine, for the specified times (abscissa) and then centrifuged through oil. Cell pellets were digested overnight in $1 \mathrm{M} \mathrm{NaOH}$ and assessed for $\left[{ }^{14} \mathrm{C}\right]$ content using standard liquid scintillation counting techniques to define pmol 6-MP accumulated per microliter cell pellet (ordinate). Data points represent the mean \pm S.D. of seven (A) or five (B) experiments done in duplicate. (C) The kinetics of ENBT1.1- and ENBT1.2-mediated $\left[{ }^{14} \mathrm{C}\right] 6$-MP uptake were determined by assessing the uptake of a range of concentrations of $\left[{ }^{14} \mathrm{C}\right] 6-\mathrm{MP}$ (abscissa) as described for (A and B). Initial rates of influx (ordinate) were estimated as the transporter-mediated uptake (calculated as the difference in cellular uptake \pm adenine) at 0.5 seconds interpolated from time course profiles as shown in (A) (ENBT1.1), or directly from the 2-second uptake time point (ENBT1.2). Data shown are the mean \pm S.D. of $N=5$ experiments.

represented by the rate of influx at 0.5 seconds extrapolated from individual time course curves. ENBT1.1-mediated $\left[{ }^{14} \mathrm{C}\right] 6-\mathrm{MP}$ accumulation was saturable with a $K_{\mathrm{m}}$ value of $163 \pm 126 \mu \mathrm{M}$ and a $V_{\max }$ value of $82 \pm 30 \mathrm{pmol} / \mu \mathrm{l}$ per second (Fig. 5C). ENBT1.2-expressing cells accumulated $\left[{ }^{14} \mathrm{C}\right] 6$-MP at less than one-half the rate of ENBT1.1-transfected cells ( $V_{\max }=32 \pm 8 \mathrm{pmol} / \mu \mathrm{l}$ per second), again reflecting the lower expression level of ENBT1.2 relative to ENBT1.1. However, 
the $K_{\mathrm{m}}$ value of $\left[{ }^{14} \mathrm{C}\right] 6-\mathrm{MP}$ for ENBT1.2-mediated transport $(188 \pm 68 \mu \mathrm{M})$ was not significantly different from that determined for ENBT1.1.

Inhibition of ENBT1-Mediated 6-MP Uptake. A number of compounds were screened initially at a single concentration for their ability to inhibit the 2-second influx of $\left[{ }^{14} \mathrm{C}\right] 6-\mathrm{MP}$ in ENBT1.1-expressing (Fig. 6A) and ENBT1.2expressing (Fig. 6B) HEK293 cells. All inhibitors tested affected ENBT1.1- and ENBT1.2-mediated 6-MP uptake similarly. The nucleoside adenosine $(1 \mathrm{mM})$ did not affect 6-MP uptake; nor did MTX, a folate analog that is used concurrently with 6-MP in the treatment of acute lymphoblastic leukemia. However, the adenosine analog 2-chloroadenosine did produce significant inhibition of 6 -MP uptake $(58 \% \pm 6 \%$ inhibition of ENBT1.1 at $1 \mathrm{mM}$ ). Nitrobenzylthioinosine, the selective ENT1 nucleoside transport inhibitor, inhibited ENBT1.1-mediated 6-MP uptake by $41 \%$ at $100 \mu \mathrm{M}$. As has been shown previously (Furukawa et al., 2015), decynium-22 was a relatively effective inhibitor of ENBT1. achieving $71 \% \pm$ $6 \%$ inhibition of ENBT1.1 at $10 \mu \mathrm{M}$. The nucleobases $6-\mathrm{TG}$ and hypoxanthine, at $1 \mathrm{mM}$, inhibited $100 \mu \mathrm{M}\left[{ }^{14} \mathrm{C}\right] 6-\mathrm{MP}$ uptake by ENBT 1.1 by $86 \% \pm 14 \%$ and $61 \% \pm 6 \%$, respectively. The 6-MP metabolite MMP also inhibited ENBT1.1-mediated 6 -MP uptake by $91 \% \pm 6 \%$ at $1 \mathrm{mM}$. 6-TG is a nucleobase analog similar in structure to 6-MP. Therefore, it is anticipated that 6-TG may also be a substrate for ENBT1, and as such should act as a competitive inhibitor of 6 -MP for the substrate recognition site. To test this, we examined the uptake of a range of concentrations of $\left[{ }^{3} \mathrm{H}\right]$ adenine by ENBT1.1 in the presence of $750 \mu \mathrm{M}$ 6-TG (Fig. 6C). $\left[{ }^{3} \mathrm{H}\right]-$ adenine uptake in the presence of 6-TG had a significantly higher apparent $K_{\mathrm{m}}$ value with no significant difference in the $V_{\max }$ value relative to data obtained in the absence of 6-TG (see Fig. 4C), indicative of competitive inhibition kinetics. Full concentration-inhibition profiles were then constructed for 6-TG, MMP, and decynium-22 (Fig. 6D) allowing the calculation of $K_{\mathrm{i}}$ values of $67 \pm 30,73 \pm 20$, and $1.0 \pm 0.4 \mu \mathrm{M}$, respectively, for their inhibition of 6-MP uptake by ENBT1.1.

ENBT1-Mediated 6-MP Efflux. To determine whether ENBT1 was bidirectional with respect to the transport of 6-MP, SLC43A3_1-transfected HEK293 cells were loaded with $100 \mu \mathrm{M}\left[{ }^{14} \mathrm{C}\right] 6-\mathrm{MP}$ for 30 seconds and assessed for the
A
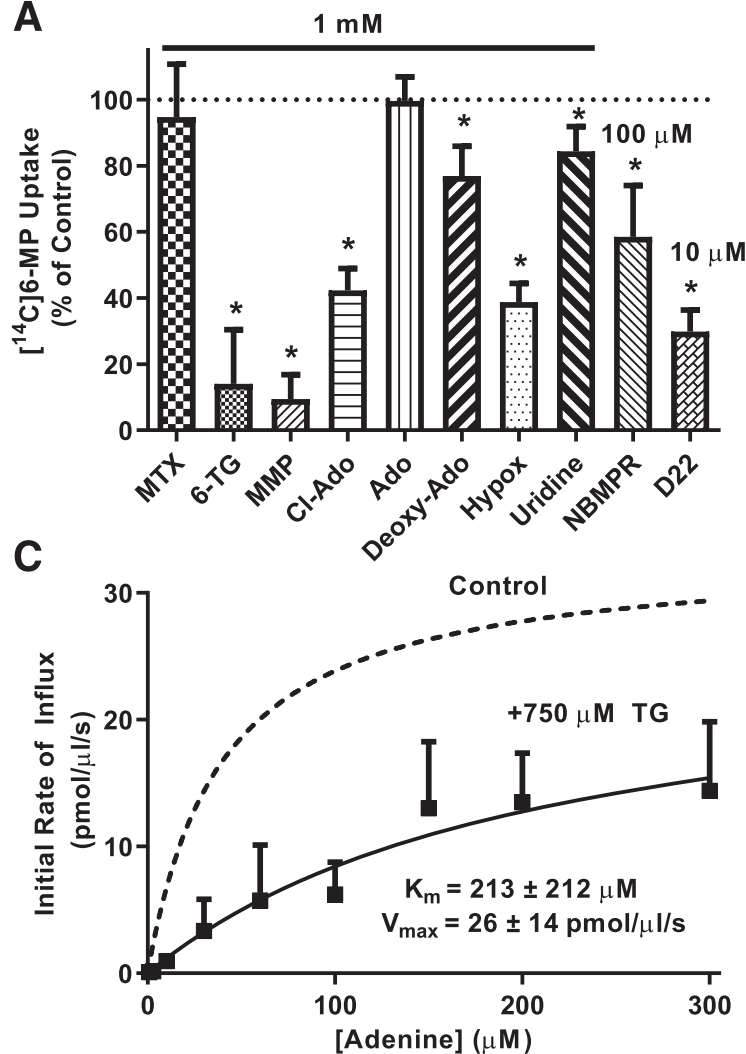

B
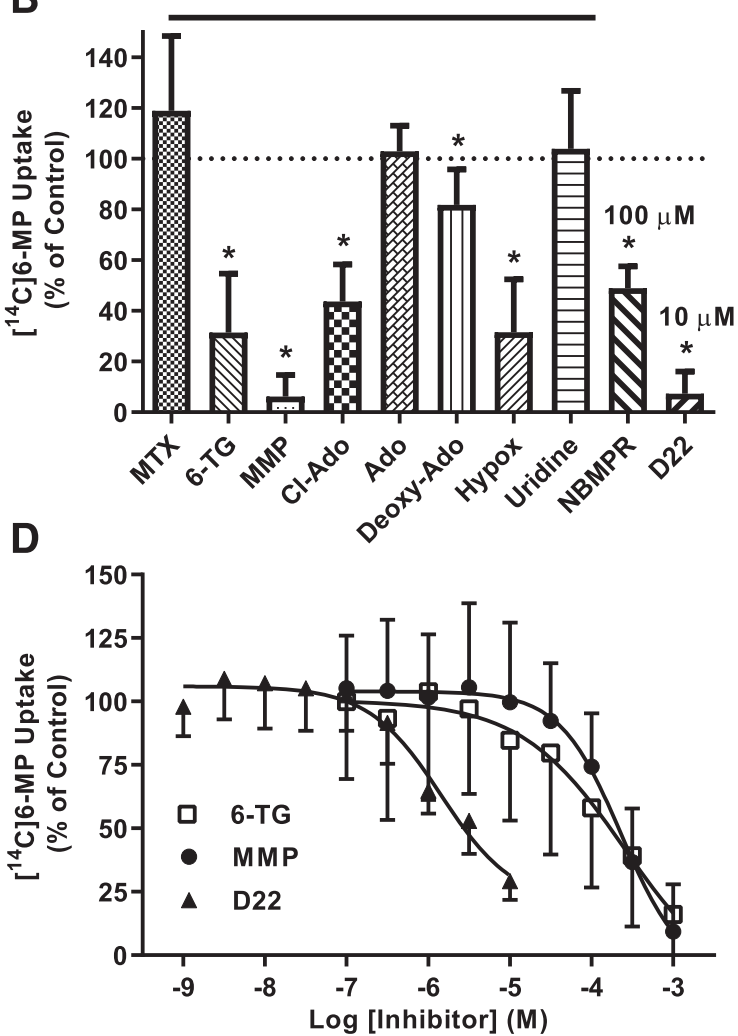

Fig. 6. Inhibition of $\left[{ }^{14} \mathrm{C}\right] 6-\mathrm{MP}$ transport by SLC43A3-transfected HEK293 cells. The uptake of $\left[{ }^{14} \mathrm{C}\right] 6-\mathrm{MP}$ by ENBT1.1 (100 $\left.\mu \mathrm{M}\right)(\mathrm{A})$ and ENBT1.2 $(30 \mu \mathrm{M})(\mathrm{B})$ was assessed using a 2-second time point in the presence and absence of the indicated concentration of MTX, 6-TG, MMP, 2-chloroadenosine (Cl-Ado), adenosine (Ado), 2-deoxyadenosine (Deoxy-Ado), hypoxanthine (Hypox), uridine, nitrobenzylthioinosine (NBMPR), or decynium-22 (D22). Data were normalized as percentage of control uptake, where $100 \%$ was defined as the uptake of $\left[{ }^{14} \mathrm{C}\right] 6$-MP in the absence of inhibitor and $0 \%$ was defined as the uptake in the presence of $1 \mathrm{mM}$ adenine. Each bar represents the mean \pm S.D. of five experiments done in duplicate; * denotes significantly different from $100 \%$ control (Student's $t$ test, $P<0.05$, corrected for multiple comparisons with the Holm-Sidak method). (C) Time courses were constructed at various concentrations of $\left[{ }^{3} \mathrm{H}\right]$ adenine in the presence of $750 \mu \mathrm{M}$ 6-TG, as described previously (see Fig. 4C). Initial rates of transport were derived from the rate of uptake at 0.5 seconds as extrapolated from the time course profiles. The dashed line indicates the analogous data obtained in the absence of 6-TG (from Fig. 4C). Data points represent mean \pm S.D. of five experiments done in duplicate. (D) A range of concentrations of 6-TG, MMP, and D22 were assessed for their ability to inhibit the 2-second uptake of $100 \mu \mathrm{M}\left[{ }^{14} \mathrm{C}\right] 6$-MP by the ENBT1.1. Data were normalized as the percentage of control uptake with $100 \%$ defined as the uptake of $100 \mu \mathrm{M}\left[{ }^{14} \mathrm{C}\right] 6-\mathrm{MP}$ in the absence of inhibitor and $0 \%$ defined as that in the presence of $1 \mathrm{mM}$ adenine. Sigmoid curves were fitted to these data for the determination of $\mathrm{IC}_{50}$ values, which were used to calculate the inhibitor $K_{\mathrm{i}}$ values shown in the text. Each point represents the mean \pm S.D. of $N=5$ experiments done in duplicate. 
rate of release of $\left[{ }^{14} \mathrm{C}\right]$ upon resuspension of cells in substratefree media. The change in intracellular 6-MP was measured with time after resuspension (Fig. 7). Due to the handling time required for this experimental procedure, the minimum efflux time that could be attained reliably was 10 seconds. From the data shown in Fig. 7 it is apparent that, in the absence of any competing compound, a new steady state was achieved prior to the first recordable time point of 10 seconds (estimated rate constant of at least 0.35 second $^{-1}$ ). This rapid rate of efflux was not unexpected given the rapid rate of 6-MP influx by ENBT1.1 in this recombinant transfection model (see Fig. $5 \mathrm{~A})$. The presence of extracellular adenine decreased the rate of 6-MP efflux significantly. The efflux time course in the presence of $1 \mathrm{mM}$ adenine fit best to a one-phase decay profile, allowing the calculation of an efflux rate constant of $0.020 \pm 0.004$ second $^{-1}$. Efflux in the presence of $100 \mu \mathrm{M}$ adenine fit best to a two-phase decay profile, with the first phase having a rate constant of $0.15 \pm 0.10$ second $^{-1}$ and the second phase having a rate constant of $0.014 \pm 0.016$ second $^{-1}$, which is not significantly different from the rate of efflux in the presence of $1 \mathrm{mM}$ adenine. When the same type of analysis was done using untransfected HEK293 cells, it was necessary to use a 10-minute loading time for $\left[{ }^{14} \mathrm{C}\right] 6-\mathrm{MP}$ to achieve comparable intracellular concentrations to those seen using the 30 -second loading time in the SLC43A3-transfected cells. Efflux of 6-MP from the HEK293 cells was dramatically slower that that observed in the SLC43A3-transfected cells, with over $70 \%$ of the initial load still retained within the cell after 3 minutes. Adenine ( $1 \mathrm{mM})$ had a slight, but significant, inhibitory effect on $\left[{ }^{14} \mathrm{C}\right] 6-\mathrm{MP}$ efflux from the untransfected HEK293 cells (rate constants

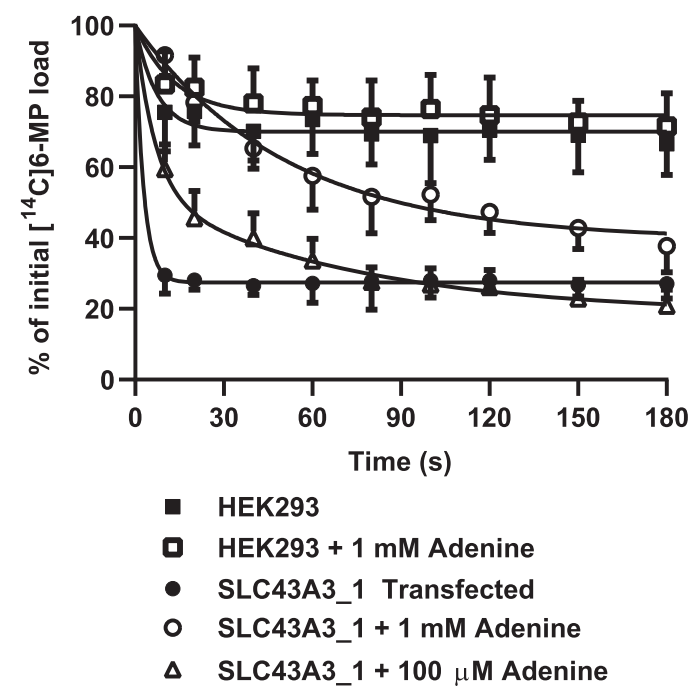

Fig. 7. 6-MP efflux by ENBT1.1. Cells were loaded with $100 \mu \mathrm{M}$ $\left[{ }^{14} \mathrm{C}\right] 6$-MP for 30 seconds (SLC43A3_1 transfected) or 10 minutes (untransfected HEK293), pelleted, and then to initiate efflux suspended in either $N$ methylglucamine buffer (control) or buffer containing either $1 \mathrm{mM}$ or $100 \mu \mathrm{M}$ adenine. Aliquots of cell suspension were centrifuged through an oil layer at the specified times (abscissa) and processed to assess intracellular $\left[{ }^{14} \mathrm{C}\right]$ content. Data are expressed as percentage of initial $\left[{ }^{14} \mathrm{C}\right] 6-\mathrm{MP}$ load (ordinate) with $100 \%$ defined as $\left[{ }^{14} \mathrm{C}\right] 6-\mathrm{MP}$ content at zero time extrapolated from the curve fit (one phase exponential decay) to the $1 \mathrm{mM}$ adenine data. One- or two-phase decay profiles were fitted to the data depending on which fit was determined to be statistically superior $(P<0.05 ; F$ test). Each point represents the mean \pm S.D. of five (control and $100 \mu \mathrm{M}$ adenine) or 10 ( $1 \mathrm{mM}$ adenine) experiments. of $0.14 \pm 0.08$ and $0.07 \pm 0.04$ second $^{-1}$ in the absence and presence of adenine, respectively), suggesting that it was mediated by endogenous nucleobase transporters.

Given the two-phase decay profile observed in the presence of $100 \mu \mathrm{M}$ adenine, and the finding that ABCC4, ABCC5, and SLC29A2 expression all declined concomitant with the increased expression of SLC43A3_1 by the HEK293 cells (Fig. 3C), we examined the effect of the ABCC4 inhibitor ceefourin-1, the ABCC5 inhibitor zaprinast, and the SLC29A2 inhibitor DY on the efflux of 6-MP from the SLC43A3_1transfected cells (Fig. 8). Ceefourin-1 had no significant effect on the initial rate of 6-MP efflux in the absence of adenine $\left(0.29 \pm 0.16\right.$ and $0.38 \pm 0.86$ second $^{-1}$, in the absence and presence of ceefourin-1, respectively) (Fig. 8A). However, ceefourin-1 did reveal a second slower phase of efflux with a rate constant of $0.02 \pm 0.04$ second $^{-1}$. The rapidity of the efflux in the absence of adenine made these data difficult to interpret due to the large errors in the calculated parameters. Therefore, the effect of ceefourin-1 was also assessed in combination with $100 \mu \mathrm{M}$ adenine. Efflux in the presence of $100 \mu \mathrm{M}$ adenine was monophasic in this case with a rate constant of $0.16 \pm 0.04$ second $^{-1}$, similar to the first phase of efflux in the presence of $100 \mu \mathrm{M}$ adenine seen previously, as reported in Fig. 7. Addition of ceefourin-1 led to a biphasic efflux profile with the initial fast component having a rate constant of $0.26 \pm 0.24$ second $^{-1}$ (which is not significantly different from that seen in the absence of ceefourin-1), and a significantly larger slower component with a rate constant of $0.014 \pm 0.014$ second $^{-1}$. In the absence of ceefourin- $1,75 \% \pm$ $2 \%$ of the efflux occurred at the faster rate in the presence of $100 \mu \mathrm{M}$ adenine. However, in the presence of ceefourin-1, this initial fast component represented only $42 \% \pm 18 \%$ of the total efflux. In contrast, the ABCC5 inhibitor zaprinast had no significant effect on 6-MP efflux in either the presence or absence of $100 \mu \mathrm{M}$ adenine (Fig. 8B). Likewise, the combination of ceefourin-1 and zaprinast (Fig. 8C) affected 6-MP efflux in a manner similar to that seen using ceefourin-1 alone. The SLC29A2 inhibitor DY also had no effect on the efflux of 6-MP (Fig. 8D).

SLC43A3 Expression and Cell Viability. If ENBT1 is critical to the cellular accumulation of $6-\mathrm{MP}$, and hence its cytotoxicity, then one might predict that SLC43A3-transfected HEK293 cells would be more sensitive to the toxic effects of 6-MP than untransfected HEK293 cells. In untransfected HEK293 cells, 6-MP had a biphasic effect on cell viability with $51 \% \pm 16 \%$ of the cells impacted by 6 -MP at an $\mathrm{EC}_{50}$ value of $5.6 \mu \mathrm{M}\left(\log \mathrm{EC}_{50}=-5.25 \pm 0.16\right)$, while the remaining cells were relatively resistant to 6 -MP with $35 \%$ $\pm 8 \%$ remaining even after 48 -hour exposure to $1 \mathrm{mM} 6$-MP (Fig. 9A). Cells transfected with the empty pcDNA3.1 plasmid had a similar biphasic profile with an $\mathrm{EC}_{50}$ value of $13.2 \mu \mathrm{M}\left(\log \mathrm{EC}_{50}=-4.878 \pm 0.064\right)$ for 6 -MP-mediated cytotoxicity, which is slightly, but significantly (extra sum-ofsquares $F$ test, $P<0.05$ ), higher than that seen for the untransfected HEK293 cells (Fig. 9A). Cells transfected with SLC43A3_1 and SLC43A3_2 also had biphasic responses to 6-MP. However, in both cases the proportion of 6-MPresistant cells after transfection with SLC43A3 was significantly lower $(50 \% \pm 26 \%$ and $23 \% \pm 8 \%$ for untransfected and SLC43A3_1-transfected cells, and 44\% $\pm 14 \%$ and $28 \% \pm$ $6 \%$ for untransfected and SLC43A3_2-transfected HEK293 cells, respectively). Transfection of HEK293 cells with SLC43A3 
A

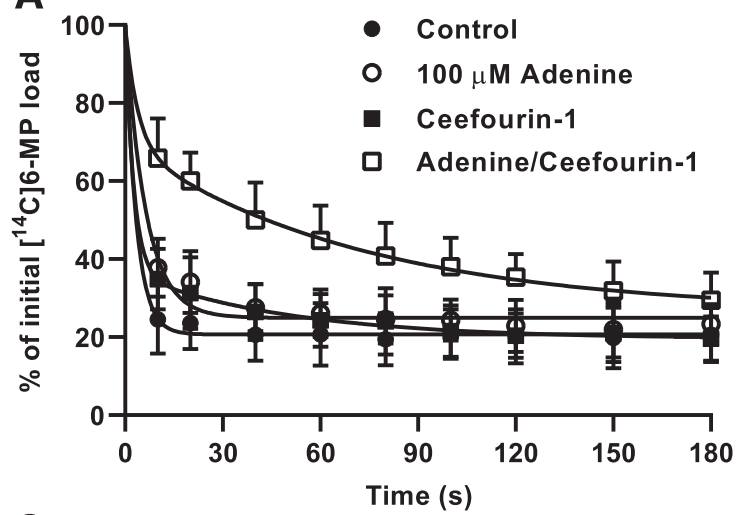

C

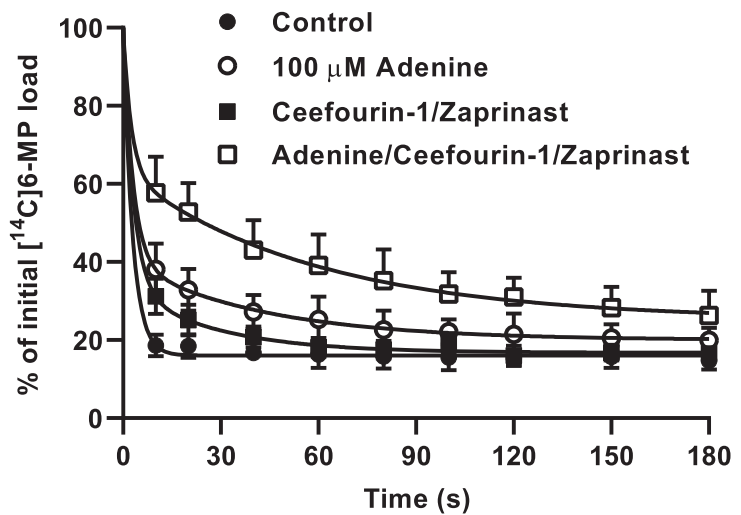

B

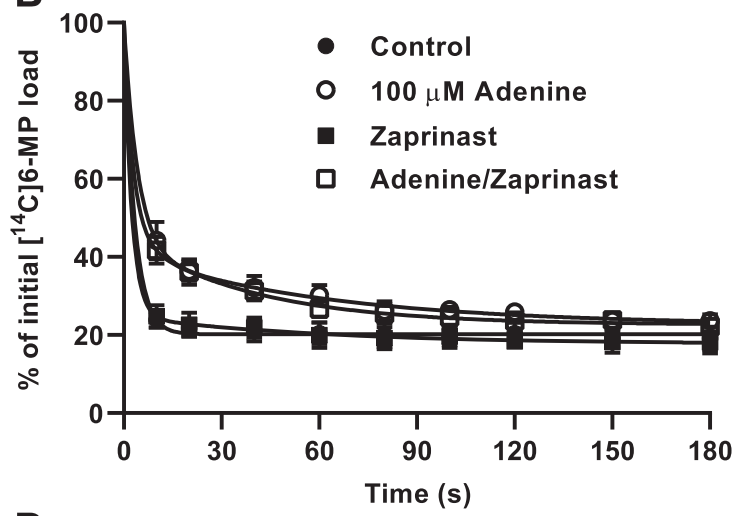

D

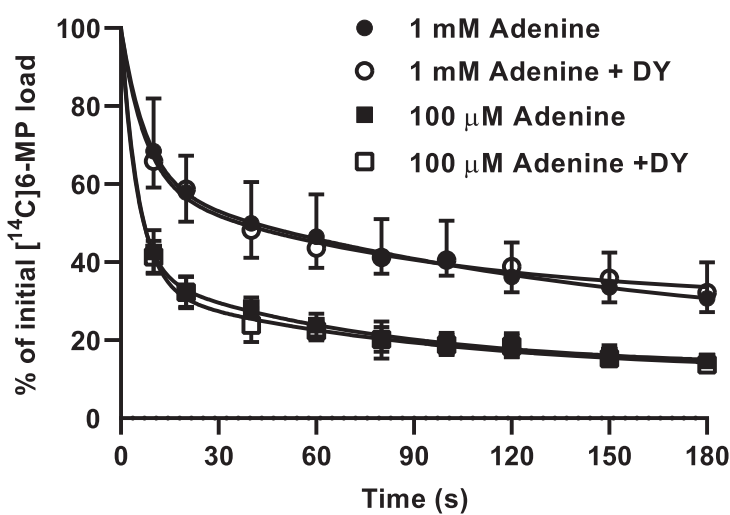

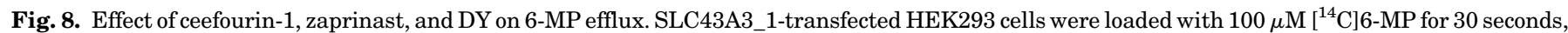

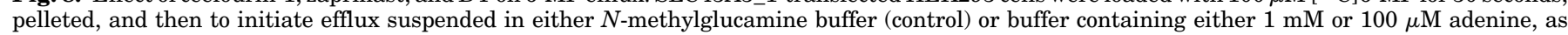

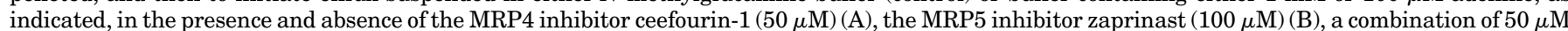

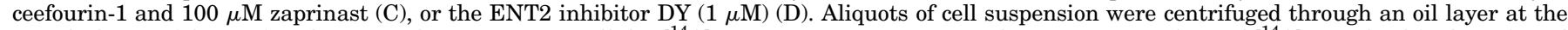

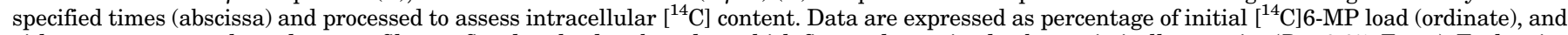

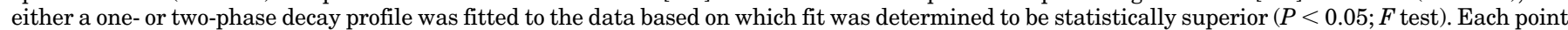
represents the mean \pm S.D. of five experiments.

also enhanced the sensitivity of the cells to the cytotoxic effects of 6-MP, by 7-fold (Fig. 9A) and 15-fold (Fig. 9B) for the SLC43A3_1- and SLC43A3_2-transfected cells, respectively. The $\log \mathrm{EC}_{50}$ values for 6-MP-mediated cytotoxicity of -6.05 \pm 0.22 and $-6.29 \pm 0.06$ were calculated from these data for the SLC43A3_1- and SLC43A3_2-transfected cells, respectively. To assess the contribution of the nucleoside/nucleobase transporters ENT1 and ENT2 to these actions of 6-MP, similar analyses were conducted in the presence and absence of DY (Fig. 9C). DY, at concentrations sufficient to completely block ENT1 and ENT2 $(1 \mu \mathrm{M})$, did not change the cytotoxicity profile of 6-MP in either the untransfected or SLC43A3_1-transfected HEK293 cells. In addition, the inclusion of G418 $(120 \mu \mathrm{g} / \mathrm{ml})$ in the media during the 48-hour cytotoxicity assay did not affect the sensitivity of either the SLC43A3_1- or the SLC43A3_2transfected cells to 6-MP (Fig. 9D).

To confirm that this increased sensitivity to 6-MP was due to the SLC43A3 transfection and not the concomitant decrease in MRP4 and MRP5 activity observed in the SLC43A3 isoform 1-transfected HEK293 cells (see Fig. 3), these studies were repeated in the presence of the MRP4 and MRP5 inhibitors ceefourin-1 and zaprinast. These inhibitors, alone or in combination, had no significant effect on the cytotoxic $\mathrm{EC}_{50}$ value of 6-MP in untransfected HEK293 cells (Fig. 10A) or cells transfected with SLC43A3_1 (Fig. 10B) (e.g., $\log \mathrm{EC}_{50}$ values of $6-\mathrm{MP}$ in HEK293 cells of $-5.21 \pm 0.08$ and $-5.17 \pm$ 0.06 in the absence and presence of ceefourin + zaprinast, respectively). However, ceefourin-1 alone or in combination with zaprinast did cause a significant increase in the relative proportion of 6-MP-resistant cells in the untransfected HEK293 population (Fig. 10A) $(29 \% \pm 2 \%$ and $40 \% \pm 2 \%$ of the cells were resistant to 6-MP in the absence and presence of ceefourin/zaprinast, respectively). For the SLC43A3_1transfected cells, while comparison of individual data points did not indicate any significant differences, curve analysis did show a similar significant shift in the resistant cell population upon treatment with the combination of ceefourin-1 and zaprinast $(38 \% \pm 2 \%$ and $49 \% \pm 2 \%$ resistant cells in the absence and presence of the inhibitors, respectively) (Fig. 10B). Suppression of ABCC4 expression (by 60\%) (Fig. 10D) by stable transfection of cells with ABCC4-targeted small interfering RNA (siRNA) also led to significant enhancement in the proportion of SLC43A3_1-transfected HEK293 cells resistant to $6-\mathrm{MP}(26 \% \pm 8 \%$ and $37 \% \pm 6 \%$ without and with siRNA, respectively) (Fig. 10C), but had no effect on the cytotoxic $\mathrm{EC}_{50}$ value of 6 -MP. However, siRNA suppression of ABCC4 in the untransfected HEK293 cells led to a significant decrease in the proportion of cells resistant to $6-\mathrm{MP}(44 \% \pm 2 \%$ and $34 \% \pm 2 \%$ without and with siRNA, respectively). There was also significant enhancement in the 
A
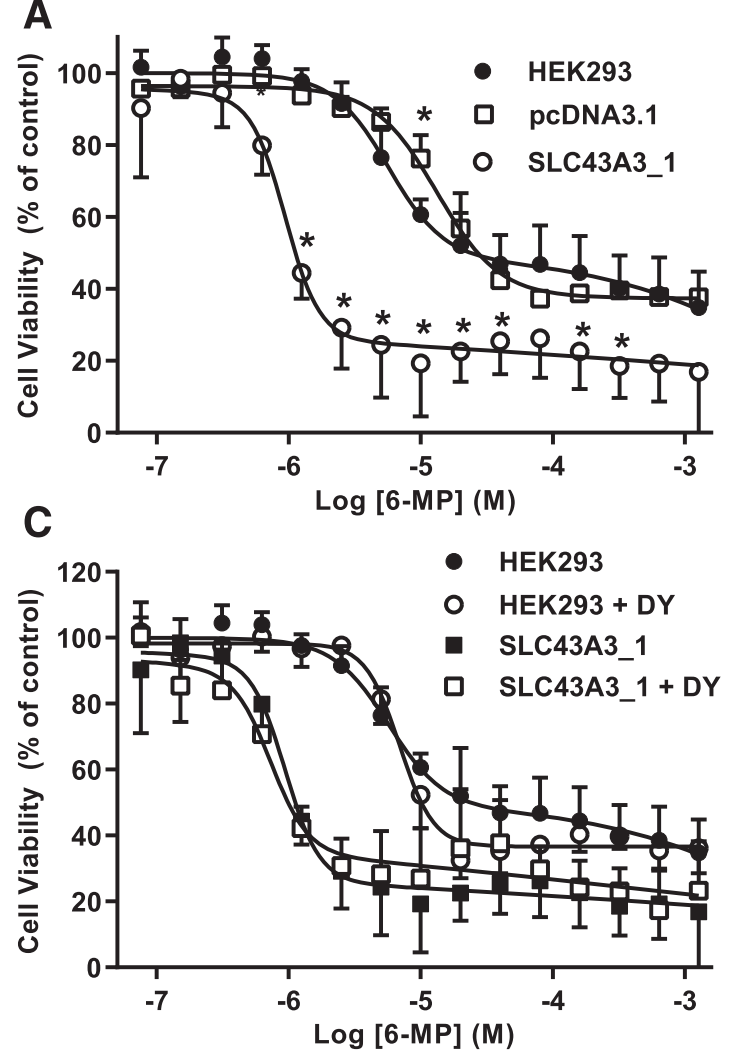

B
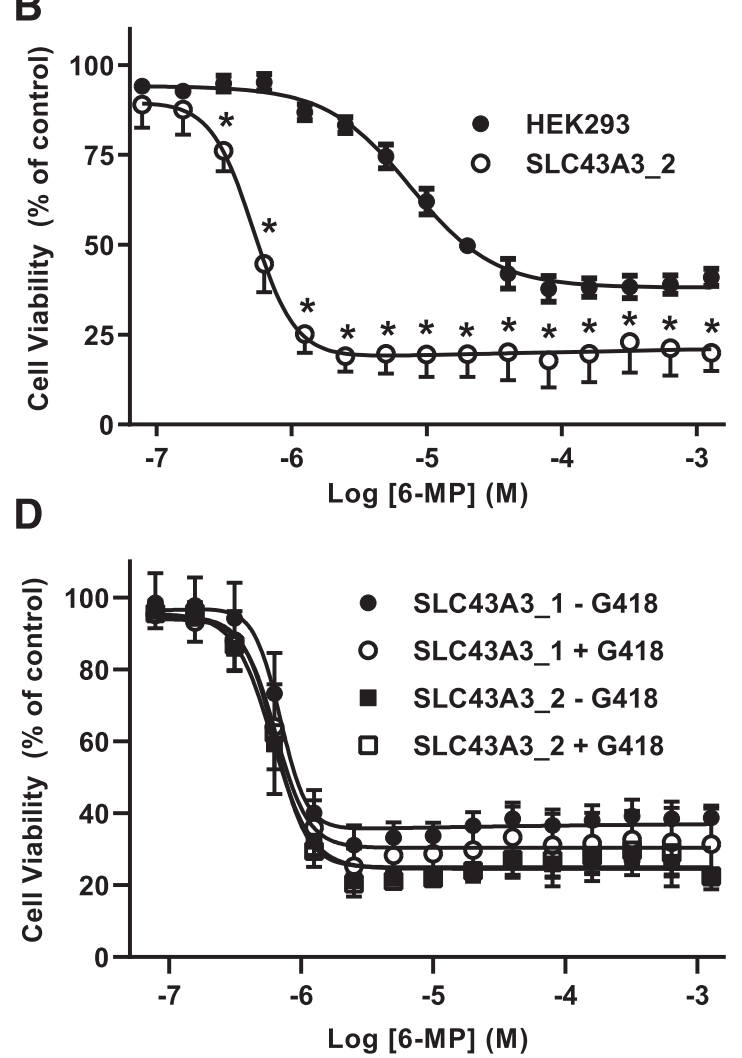

Fig. 9. SLC43A3 transfection of HEK293 cells significantly enhances the cytotoxicity of 6-MP. HEK293 cells and cells transfected with empty pcDNA3.1 plasmid or SLC43A3_1 (A) or SLC43A3_2 (B) were plated at a density of $5 \times 10^{4}$ cells/well in 24-well plates and incubated with a range of concentrations of 6-MP (abscissa) for 48 hours at $37^{\circ} \mathrm{C}$ in a humidified incubator $\left(5 \% \mathrm{CO}_{2} / 95 \%\right.$ air). Cell viability was assessed using the 3-(4,5-dimethylthiazol-2-yl)2,5-diphenyltetrazolium bromide assay, and expressed as a percentage of the cell viability measured at 48 hours in the absence of 6-MP (percentage of control; ordinate). Biphasic dose-response curves were fitted to these data, and each point represents the mean \pm S.D. of five experiments; * denotes significant difference between HEK293 cells and SLC43A3-transfected cells (Student's $t$ test, $P<0.05$, corrected for multiple comparisons with the Holm-Sidak method). (C) Effect of DY on the cytotoxicity of 6-MP. HEK293 cells and cells transfected with SLC43A3_1 were incubated with a range of concentrations of 6-MP in the absence and presence of the ENT1/ENT2 blocker DY $(1 \mu \mathrm{M})$. Cell viability was assessed and data are presented as described for $(\mathrm{A}$ and B) $(N=5)$. (D) Effect of G418 on the cytotoxicity of 6-MP in SLC43A3 1- and SLC43A3 2-transfected HEK293 cells. Cell viability was assessed upon incubation with the indicated concentrations of 6-MP for 48 hours, as described for (A and B), in the presence (+) and absence (-) of $120 \mu \mathrm{g} / \mathrm{ml} \mathrm{G418}(N=5)$.

cytotoxicity of 20 and $30 \mu \mathrm{M} 6$-MP in the siRNA-transfected cells, but there was no change in the overall $\mathrm{EC}_{50}$ value of 6-MP for the sensitive population of cells (due to the increase in the relative percentage of 6-MP-sensitive cells after siRNA transfection).

\section{Discussion}

Both isoforms of SLC43A3 encode proteins (ENBT1.1 and ENBT1.2) that mediate the uptake of the endogenous nucleobase adenine and the nucleobase analog 6-MP with comparable $K_{\mathrm{m}}$ values (Fig. 4C; Fig. 5C). Therefore, the 13 amino acid insert in the first extracellular loop of ENBT1.2 does not directly affect substrate affinity or transporter function. The $K_{\mathrm{m}}$ value for adenine determined herein was similar to that reported for the SLC43A3_1-encoded ENBT1 expressed in MDCKII cells (Furukawa et al., 2015), and is also similar to the value we reported for an ENBT1-like transporter in human microvascular endothelial cells (Bone and Hammond, 2007). Transfection of HEK293 cells with SLC43A3 (either isoform) resulted in dramatic enhancement in the ability of 6-MP to decrease cell viability (Fig. 9). This indicates that ENBT1 activity has a direct impact on the cytotoxicity of 6-MP, and that variations in SLC43A3 expression may modify the therapeutic effectiveness of 6-MP. However, it is notable that cells transfected with SLC43A3_2 had a similar shift in 6-MP cytotoxicity as cells transfected with SLC43A3_1, even though the level of transfection with SLC43A3_1 was 6-fold higher than that seen for SLC43A3_2 (Fig. 2), and the SLC43A3_1 cells had an $\sim 2.5$-fold higher rate of uptake of 6-MP than the SLC43A3_2 cells (Fig. 5C). This may indicate that ENBT1-mediated 6-MP transport is rate limiting for 6-MP cytotoxicity only up to a certain point, after which the intracellular metabolic pathways are saturated and the rate of 6-MP metabolism becomes limiting.

Stable transfection of HEK293 cells with SLC43A3 (either isoform) decreased the expression of SLC29A2 (ENT2), ABCC4 (MRP4), and ABCC5 (MRP5) (Fig. 3, C and D). Transfection with SLC43A3_2 also caused downregulation of SLC29A4 (ENT4). The downregulation of ABCC5 may be due to the transfection or influence of chronic exposure to G418, since similar downregulation was seen in vector-only transfected cells (Fig. 3B). The vector controls did not exhibit downregulation of the other genes seen in the SLC43A3transfected cells. The downregulation of ENT2 and MRP4 may reflect compensation by the cells to the enhanced availability of nucleobases via ENBT1 to support intracellular metabolism (Senyavina and Tonevitskaya, 2015). Both of 

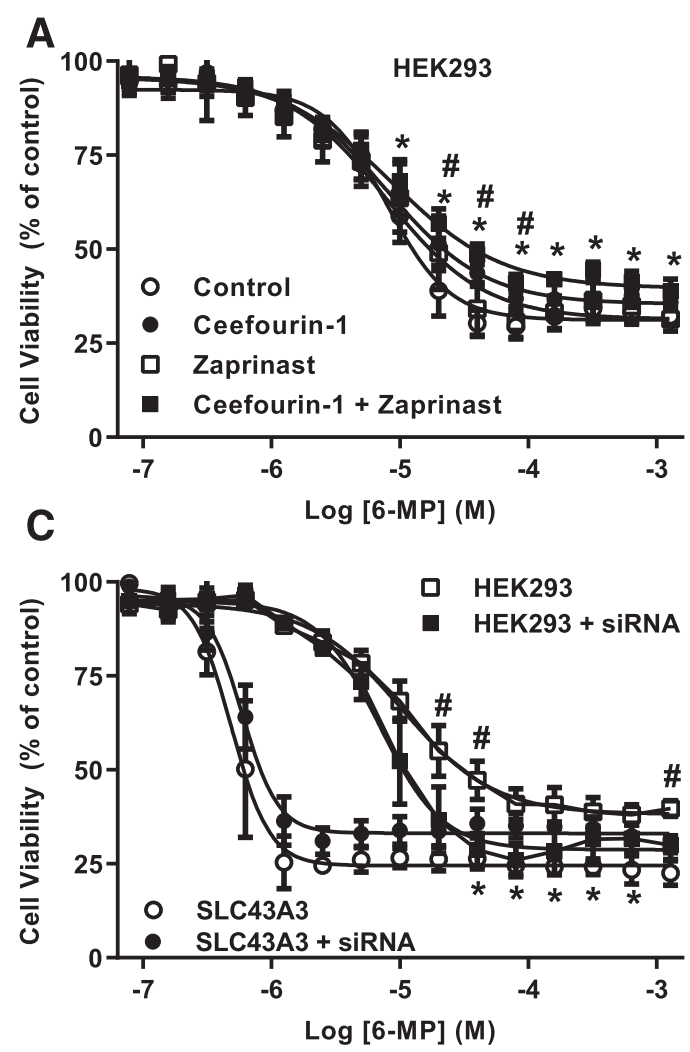

B
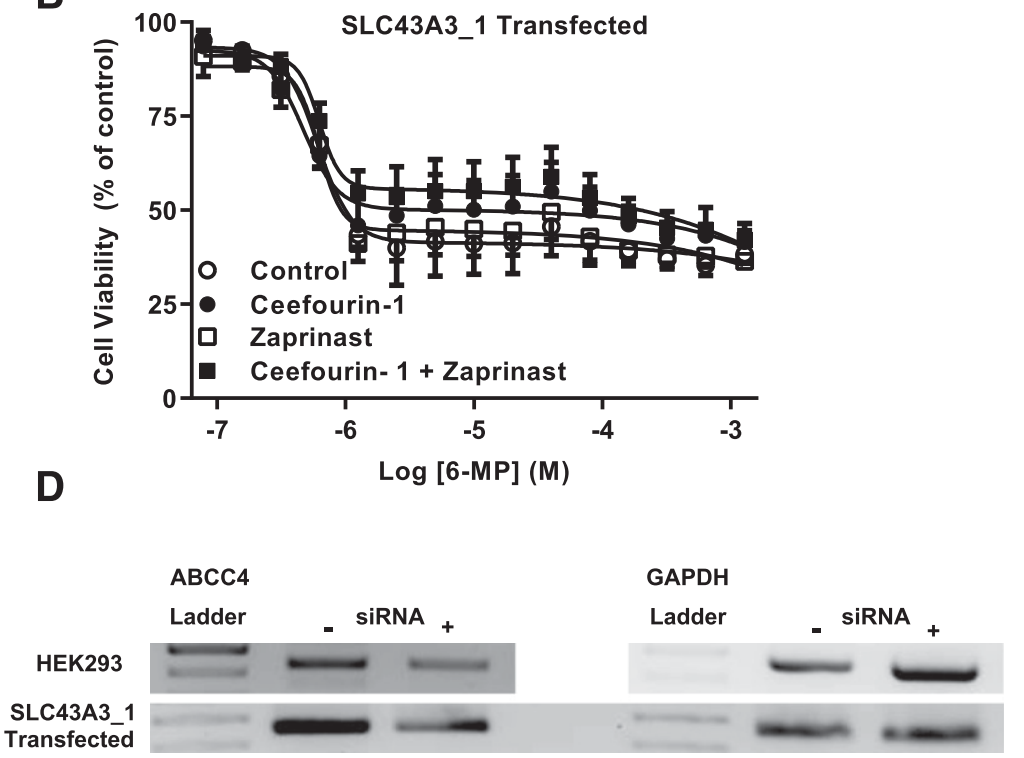

Fig. 10. Effect of MRP4 and MRP5 inhibition on the cytotoxicity of 6-MP. HEK293 cells (A) and cells transfected with SLC43A3_1 (B) were exposed to a range of concentrations of 6-MP for 48 hours in the absence (control) and presence of ceefourin-1 (50 $\mu \mathrm{M})$, zaprinast (100 $\mu \mathrm{M})$, or a combination of both, and then assessed for cell viability as described in Fig. 9; * denotes significant difference between control and ceefourin-1 + zaprinast and \# denotes significant difference between control and ceefourin-1 alone (Student's $t$ test, $P<0.05$, corrected for multiple comparisons with the Holm-Sidak method, $N=6$ ). (C) HEK293 cells and cells transfected with SLC43A3_1 were stably transfected with ABCC4 (MRP4)-targeted siRNA. The cytotoxicity of a range of concentrations of 6-MP was then assessed in these cells lines as described in Fig. 9; * denotes significant effect of siRNA in SLC43A3_1-transfected HEK293 cells and \# denotes significant effect of siRNA in untransfected HEK293 cells (Student's $t$ test, $P<0.05$, corrected for multiple comparisons with the Holm-Sidak method, $N=5$ ). (D) ABCC4 transcript levels ( \pm siRNA transfection) in the untransfected and SLC43A3_1-transfected HEK293 cells used for the experiments shown in (C). Glyceraldehyde-3-phosphate dehydrogenase (GAPDH) transcript levels were determined in parallel for each cell line to correct for loading differences. Densitometry analysis indicates that the ABCC4 transcript was suppressed by 60\% in the siRNA-transfected cells.

these transporters are known to mediate the flux of 6-MP (Janke et al., 2008; Peng et al., 2008; Ansari et al., 2009; Yao et al., 2011; Tanaka et al., 2015). However, in terms of 6-MP sensitivity, a decrease in ENT2 activity would actually lead to reduced cellular uptake of 6-MP, and consequently decreased cytotoxicity-opposite to that observed in the present study. Human ENT2 has a very low affinity for 6-MP ( $>1 \mathrm{mM} K_{\mathrm{m}}$ ) relative to ENBT1 (Yao et al., 2011), making it unlikely to contribute to 6-MP uptake at clinically relevant concentrations. Furthermore, we showed that the ENT1/ENT2 inhibitor DY impacted neither the uptake nor the efflux of 6-MP; nor did it affect 6 -MP cytotoxicity. The reason for the downregulation of ENT4 in the SLC43A3_2transfected cells is obscure. ENT4 is predominantly a monoamine transporter at neutral $\mathrm{pH}$ and transports adenosine under acidic $\mathrm{pH}$ conditions (Zhou et al., 2007, 2010), and nucleobases are not substrates for ENT4. On the other hand, the efflux pumps MRP4 and MRP5 are known to be associated with 6-MP resistance (Chen et al., 2001; Reid et al., 2003; Fukuda and Schuetz, 2012), and their decreased expression was thus considered a potential factor in the increased 6-MP cytotoxicity observed. The MRP5 inhibitor zaprinast had no effect on 6-MP uptake, efflux, or cytotoxicity, suggesting that MRP5 is not contributing to the 6-MP activity in this model. However, the MRP4 inhibitor ceefourin-1 significantly decreased the rate of efflux of 6-MP from SLC43A3-transfected HEK293 cells (Fig. 8A), suggesting that MRP4 does contribute to 6-MP efflux in this model. This conjecture is supported by the finding that transfection of HEK293 cells with siRNA for ABCC4 led to an increase in their sensitivity to 6-MP at higher concentrations (Fig. 10C). However, MRP4mediated efflux of 6-MP is slower than that mediated by ENBT1, and only has an impact at lower levels of ENBT1 activity (such as when ENBT1 is partially inhibited with $100 \mu \mathrm{M}$ adenine). The dominance of ENBT1 in this model is also apparent from the finding that ceefourin-1 had no effect on the cytotoxicity of 6-MP in SLC43A3-transfected cells (Fig. 10). These data indicate that the compensatory downregulation of ABCC4 in the SLC43A3-transfected cells is not contributing to the enhanced sensitivity of the SLC43A3-transfected cells to 6-MP. Interestingly, incubation of the untransfected HEK293 cells with MRP4 inhibitors resulted in a significant increase in the relative proportion of 6-MP-resistant cells (Fig. 10A). A similar trend was seen for the SLC43A3_1-transfected cells. MRP4 inhibition may lead to increased intracellular cAMP (an endogenous substrate for MRP4), causing cell cycle arrest in HEK293 cells, as has been reported in other cell lines (Copsel et al., 2011; Zhao et al., 2014), such that more of the 
cells enter a quiescent phase where they are not affected by 6 -MP.

The significant contribution of ENBT1 to the cellular accumulation of 6-MP suggests that changes in the expression of this transporter may impact the therapeutic effectiveness of 6-MP. Little is known about the regulation of SLC43A3 expression. However, the striking downregulation (10-fold) of SLC43A3 expression in cells transfected with pcDNA3.1 only (vector control) (Fig. 3A) suggests that it is transcriptionally regulated. This decrease in expression also impacts the cellular sensitivity to 6-MP, as evidenced by a decrease in 6-MP cytotoxicity in the vector-transfected cells (Fig. 9A). It is possible that metabolic stress associated with expression of aminoglycoside phosphotransferase (mediating the G418 resistance) in the transfected cells (Yallop and Svendsen, 2001; Veraitch and Al-Rubeai, 2005), and/or the chronic exposure to G418, may be responsible for this downregulation. We have shown previously that the uptake of hypoxanthine by ENBT1 in microvascular endothelial cells is decreased by the oxidative stress associated with hypoxia (Bone et al., 2014). This may have ramifications for use of nucleobase analogs in cancer therapy since there is a strong association between oxidative stress and cancer progression (Sosa et al., 2013).

Given the importance of ENBT1 to the cellular uptake of 6-MP, this system may be a target for drug-drug interactions that impact 6-MP therapeutic activity. Both isoforms (ENBT1.1 and ENBT1.2) had comparable sensitivities to the inhibitors tested (Fig. 6). We confirmed that MTX and adenosine do not have affinity for ENBT1. MTX, as a folate analog, would not be expected to inhibit ENBT1, but the confirmation of no direct drug-drug interactions via ENBT1 is important given that MTX is used in conjunction with 6-MP for chemotherapy. Likewise, the ENT1 blocker nitrobenzylthioinosine was relatively ineffective against 6-MP uptake by ENBT1. The finding that adenosine and uridine had no inhibitory activity also confirms that ENT1, ENT2, CNT1, CNT2, and CNT3 are not involved in 6-MP uptake in our model. However, 2-chloroadenosine did significantly inhibit 6-MP uptake. This adenosine analog can induce apoptosis in B-cells and is resistant to metabolism by adenosine deaminase (Bastin-Coyette et al., 2008), making it more metabolically stable than adenosine. 2-Chloroadenosine has also been reported to inhibit an ENBT1-like transporter in a nucleoside transport deficient mutant subline of porcine kidney 15 cells (Hoque et al., 2008). It is possible that the addition of the halogen group leads to enhanced recognition by nucleobase transporters. In this regard, 2-chloroadenosine has higher affinity for the nucleoside transporter ENT2 than it does for ENT1 (Hammond, 1991), and ENT2 has a higher affinity for nucleobases than does ENT1 (Yao et al., 2011). This chemical characteristic may be something to consider in the search for selective inhibitors of ENBT1. Also of interest is the finding that the 6-MP metabolite, MMP, generated through the methylation of 6-MP by TPMT inhibits ENBT1. ENBT1.1 is bidirectional in that we showed it can also mediate the efflux of 6-MP from cells. Therefore, it is possible that removal of MMP from cells via ENBT1 may contribute to cellular resistance to 6-MP, depending on the relative affinity of MMP for the transporter compared with subsequent intracellular enzymatic processes. It may be of value in future studies to determine how intracellular MMP affects the rate of uptake of 6-MP. A complex interplay between these two systems may explain some of the variability seen in the assessment of TPMT-mediated metabolism of 6-MP (KarasKuzelicki and Mlinaric-Rascan, 2009; Chouchana et al., 2014). We have also determined that 6-TG inhibits 6-MP uptake and is itself a likely substrate for ENBT1. 6-TG is not as commonly used in the therapy of acute lymphoblastic leukemia due to the greater toxicity associated with its use (Vora et al., 2006; Stork et al., 2010), but it is used for the treatment of inflammatory bowel diseases such as Crohn's disease (Bär et al., 2013).

In summary, we have established that both variants of ENBT1 can mediate the transport of 6-MP and that increased SLC43A3 expression enhances the ability of 6-MP to induce cell death. There are no apparent differences in the ENBT1 variants in terms of their affinity for adenine or 6-MP. Therefore, further studies examining whether differences in SLC43A3 expression contribute to the variability in 6-MP effectiveness when used in the treatment of leukemia and inflammatory bowel disorders are clearly warranted.

\section{Acknowledgments}

This work was aided by the excellent technical support of Monika Dabrowska. We thank Dr. Elaine Leslie (Physiology, University of Alberta) for the generous gift of ABCC4 siRNA. Nicholas Ruel acknowledges support received for his graduate training from the Faculty of Medicine and Dentistry, University of Alberta.

\section{Authorship Contributions}

Participated in research design: Ruel, Nguyen, Hammond.

Conducted experiments: Ruel, Nguyen, Vilas.

Contributed new reagents or analytic tools: Vilas.

Performed data analysis: Ruel, Hammond.

Wrote or contributed to the writing of the manuscript: Ruel, Hammond.

\section{References}

Ansari M, Sauty G, Labuda M, Gagné V, Laverdière C, Moghrabi A, Sinnett D, and Krajinovic M (2009) Polymorphisms in multidrug resistance-associated protein gene 4 is associated with outcome in childhood acute lymphoblastic leukemia. Blood 114:1383-1386.

Bär F, Sina C, and Fellermann K (2013) Thiopurines in inflammatory bowel disease revisited. World J Gastroenterol 19:1699-1706.

Bastin-Coyette L, Smal C, Cardoen S, Saussoy P, Van den Neste E, and Bontemps F (2008) Mechanisms of cell death induced by 2-chloroadenosine in leukemic B-cells. Biochem Pharmacol 75:1451-1460.

Bodoy S, Fotiadis D, Stoeger C, Kanai Y, and Palacín M (2013) The small SLC43 family: facilitator system 1 amino acid transporters and the orphan EEG1. Mol Aspects Med 34:638-645.

Bone DB, Antic M, Vilas G, and Hammond JR (2014) Oxidative stress modulates nucleobase transport in microvascular endothelial cells. Microvasc Res 95:68-75.

Bone DB and Hammond JR (2007) Nucleoside and nucleobase transporters of primary human cardiac microvascular endothelial cells: characterization of a novel nucleobase transporter. Am J Physiol Heart Circ Physiol 293:H3325-H3332.

Burckhardt G (2012) Drug transport by organic anion transporters (OATs). Pharmacol Ther 136:106-130.

Chen ZS, Lee K, and Kruh GD (2001) Transport of cyclic nucleotides and estradiol $17-\beta$-D-glucuronide by multidrug resistance protein 4 . Resistance to 6-mercaptopurine and 6-thioguanine. $J$ Biol Chem 276:33747-33754.

Cheng Y and Prusoff WH (1973) Relationship between the inhibition constant $\left(K_{I}\right)$ and the concentration of inhibitor which causes 50 per cent inhibition $\left(I_{50}\right)$ of an enzymatic reaction. Biochem Pharmacol 22:3099-3108.

Chouchana L, Narjoz C, Roche D, Golmard JL, Pineau B, Chatellier G, Beaune P, and Loriot MA (2014) Interindividual variability in TPMT enzyme activity: 10 years of experience with thiopurine pharmacogenetics and therapeutic drug monitoring. Pharmacogenomics 15:745-757.

Copsel S, Garcia C, Diez F, Vermeulem M, Baldi A, Bianciotti LG, Russel FGM, Shayo C, and Davio C (2011) Multidrug resistance protein 4 (MRP4/ABCC4) regulates cAMP cellular levels and controls human leukemia cell proliferation and differentiation. J Biol Chem 286:6979-6988.

Duan P and You G (2009) Novobiocin is a potent inhibitor for human organic anion transporters. Drug Metab Dispos 37:1203-1210.

Fukuda Y and Schuetz JD (2012) ABC transporters and their role in nucleoside and nucleotide drug resistance. Biochem Pharmacol 83:1073-1083.

Furukawa J, Inoue K, Maeda J, Yasujima T, Ohta K, Kanai Y, Takada T, Matsuo H, and Yuasa H (2015) Functional identification of SLC43A3 as an equilibrative nucleobase transporter involved in purine salvage in mammals. Sci Rep 5:15057.

Griffith DA and Jarvis SM (1993) High affinity sodium-dependent nucleobase transport in cultured renal epithelial cells $\left(\mathrm{LLC}_{-} \mathrm{PK}_{1}\right)$. J Biol Chem 268: 20085-20090. 
Hammond JR (1991) Comparative pharmacology of the nitrobenzylthioguanosinesensitive and -resistant nucleoside transport mechanisms of Ehrlich ascites tumor cells. J Pharmacol Exp Ther 259:799-807.

Hoque KM, Chen L, Leung GP, and Tse CM (2008) A purine-selective nucleobase/ nucleoside transporter in PK15NTD cells. Am J Physiol Regul Integr Comp Physiol 294:R1988-R1995.

Janke D, Mehralivand S, Strand D, Gödtel-Armbrust U, Habermeier A, Gradhand U, Fischer C, Toliat MR, Fritz P, Zanger UM, et al. (2008) 6-mercaptopurine and 9-(2-phosphonyl-methoxyethyl) adenine (PMEA) transport altered by two missense mutations in the drug transporter gene ABCC4. Hum Mutat 29:659-669.

Karas-Kuzelicki N and Mlinaric-Rascan I (2009) Individualization of thiopurine therapy: thiopurine $S$-methyltransferase and beyond. Pharmacogenomics 10 1309-1322

Kingston RE, Chen CA, and Rose JK (2003) Calcium phosphate transfection. Curr Protoc Mol Biol 63:9.1.1-9.1.11.

Mori S, Ohtsuki S, Takanaga H, Kikkawa T, Kang YS, and Terasaki T (2004) Organic anion transporter 3 is involved in the brain-to-blood efflux transport of thiopurine nucleobase analogs. J Neurochem 90:931-941.

Nagai K, Nagasawa K, Kihara Y, Okuda H, and Fujimoto S (2007) Anticancer nucleobase analogues 6-mercaptopurine and 6-thioguanine are novel substrates for equilibrative nucleoside transporter 2. Int J Pharm 333:56-61.

Omasits U, Ahrens CH, Müller S, and Wollscheid B (2014) Protter: interactive protein feature visualization and integration with experimental proteomic data. Bioinformatics 30:884-886.

Peng XX, Shi Z, Damaraju VL, Huang XC, Kruh GD, Wu HC, Zhou Y, Tiwari A, Fu L, Cass CE, et al. (2008) Up-regulation of MRP4 and down-regulation of influx transporters in human leukemic cells with acquired resistance to 6-mercaptopurine. Leuk Res 32:799-809.

Reid G, Wielinga P, Zelcer N, De Haas M, Van Deemter L, Wijnholds J, Balzarini J, and Borst P (2003) Characterization of the transport of nucleoside analog drugs by the human multidrug resistance proteins MRP4 and MRP5. Mol Pharmacol 63: 1094-1103.

Senyavina NV and Tonevitskaya SA (2015) Effect of hypoxanthine on functional activity of nucleoside transporters ENT1 and ENT2 in caco-2 polar epithelial intestinal cells. Bull Exp Biol Med 160:160-164.

Sosa V, Moliné T, Somoza R, Paciucci R, Kondoh H, and LLeonart ME (2013) Oxidative stress and cancer: an overview. Ageing Res Rev 12:376-390.

Stork LC, Matloub Y, Broxson E, La M, Yanofsky R, Sather H, Hutchinson R, Heerema NA, Sorrell AD, Masterson M, et al. (2010) Oral 6-mercaptopurine versus oral 6-thioguanine and veno-occlusive disease in children with standard-risk acute lymphoblastic leukemia: report of the Children's Oncology Group CCG-1952 clinical trial. Blood 115:2740-2748.

Tanaka Y, Manabe A, Fukushima H, Suzuki R, Nakadate H, Kondoh K, Nakamura K, Koh K, Fukushima T, Tsuchida M, et al. (2015) Multidrug resistance protein 4 (MRP4) polymorphisms impact the 6-mercaptopurine dose tolerance during maintenance therapy in Japanese childhood acute lymphoblastic leukemia. Pharmacogenomics $J$ 15:380-384.

Thul PJ, Åkesson L, Wiking M, Mahdessian D, Geladaki A, Ait Blal H, Alm T, Asplund A, Björk L, Breckels LM, et al. (2017) A subcellular map of the human proteome. Science 356:eaal3321.

Veraitch FS and Al-Rubeai M (2005) Enhanced growth in NS0 cells expressing aminoglycoside phosphotransferase is associated with changes in metabolism, productivity, and apoptosis. Biotechnol Bioeng 92:589-599.

Vora A, Mitchell CD, Lennard L, Eden TO, Kinsey SE, Lilleyman J, and Richards SM; Medical Research Council; National Cancer Research Network Childhood Leukaemia Working Party (2006) Toxicity and efficacy of 6-thioguanine versus 6-mercaptopurine in childhood lymphoblastic leukaemia: a randomised trial. Lancet 368:1339-1348.

Ward JL, Sherali A, Mo ZP, and Tse CM (2000) Kinetic and pharmacological properties of cloned human equilibrative nucleoside transporters, ENT1 and ENT2, stably expressed in nucleoside transporter-deficient PK15 cells. Ent2 exhibits a low affinity for guanosine and cytidine but a high affinity for inosine. J Biol Chem $\mathbf{2 7 5}$ : 8375-8381.

Yallop CA and Svendsen I (2001) The effects of G418 on the growth and metabolism of recombinant mammalian cell lines. Cytotechnology 35:101-114.

Yamamoto S, Inoue K, Murata T, Kamigaso S, Yasujima T, Maeda JY, Yoshida Y, Ohta KY, and Yuasa H (2010) Identification and functional characterization of the first nucleobase transporter in mammals: implication in the species difference in the intestinal absorption mechanism of nucleobases and their analogs between higher primates and other mammals. J Biol Chem 285:6522-6531.

Yao SY, Ng AM, Cass CE, Baldwin SA, and Young JD (2011) Nucleobase transport by human equilibrative nucleoside transporter 1 (hENT1). J Biol Chem 286: $32552-32562$

Young JD, Yao SY, Baldwin JM, Cass CE, and Baldwin SA (2013) The human concentrative and equilibrative nucleoside transporter families, SLC28 and SLC29. Mol Aspects Med 34:529-547.

Zhao X, Guo Y, Yue W, Zhang L, Gu M, and Wang Y (2014) ABCC4 is required for cell proliferation and tumorigenesis in non-small cell lung cancer. OncoTargets Ther 7: 343-351.

Zhou M, Duan H, Engel K, Xia L, and Wang J (2010) Adenosine transport by plasma membrane monoamine transporter: reinvestigation and comparison with organic cations. Drug Metab Dispos 38:1798-1805.

Zhou M, Xia L, Engel K, and Wang J (2007) Molecular determinants of substrate selectivity of a novel organic cation transporter (PMAT) in the SLC29 family. J Biol Chem 282:3188-3195.

Address correspondence to: Dr. James R. Hammond, Department of Pharmacology, 9-70 Medical Sciences Building, University of Alberta, Edmonton, AB T6G 2H7, Canada. E-mail: james.hammond@ualberta.ca 